\title{
New Trade Models, Same Old Gains?*
}

\author{
Costas Arkolakis Arnaud Costinot Andrés Rodríguez-Clare \\ Yale and NBER MIT and NBER Penn State and NBER
}

December 29, 2010

\begin{abstract}
Micro-level data have had a profound influence on research in international trade over the last ten years. In many regards, this research agenda has been very successful. New stylized facts have been uncovered and new trade models have been developed to explain these facts. In this paper we investigate to which extent answers to new micro-level questions have affected answers to an old and central question in the field: How large are the welfare gains from trade? A crude summary of our results is: "So far, not much."
\end{abstract}

*We thank Marios Angeletos, Pol Antras, Andy Atkeson, Ariel Burstein, Dave Donaldson, Maya Eden, Gita Gopinath, Gene Grossman, Pete Klenow, Ivana Komunjer, Sam Kortum, Giovanni Maggi, Ellen McGrattan, Kim Ruhl, Nancy Stokey, Jim Tybout, Jonathan Vogel, Kei-Mu Yi, Ivan Werning, as well as various seminar participants for helpful suggestions. Andrés Rodríguez-Clare thanks the Human Capital Foundation (http://www.hcfoundation.ru) for support. All errors are our own. 


\section{Introduction}

What share of firms export? How large are exporters? How many products do they export? Over the last ten years, micro-level data have allowed trade economists to shed light on these and other micro-level questions. The objective of our paper is to look back at this research agenda and investigate to what extent answers to new micro-level questions have affected our answers to an old and central question in international trade: How large are the welfare gains from trade? A crude summary of our results is: "So far, not much."

The main contribution of our paper is to demonstrate that, independently of their microlevel implications, the welfare predictions of an important class of trade models only depend on two sufficient statistics: $(i)$ the share of expenditure on domestic goods, $\lambda$, which is equal to one minus the import penetration ratio; and $(i i)$ an elasticity of imports with respect to variable trade $\operatorname{costs}, \varepsilon$, which we refer to as the "trade elasticity". Formally, we show that, within this class of models, the change in real income, $\widehat{W} \equiv W^{\prime} / W$, associated with any foreign shock can be computed as

$$
\widehat{W}=\widehat{\lambda}^{1 / \varepsilon}
$$

where $\widehat{\lambda} \equiv \lambda^{\prime} / \lambda$ is the change in the share of domestic expenditure.

Armed with estimates of the trade elasticity, which can be obtained from the large gravity literature, Equation (1) offers a simple way to evaluate the welfare gains from trade. Since the share of domestic expenditure under autarky would be equal to one, the total size of the gains from trade, defined as the absolute value of the percentage change in real income as we move from the observed equilibrium to autarky, is simply $1-\lambda^{-1 / \varepsilon}$. Consider, for example, the United States for the year 2000. The import penetration ratio was $7 \%$, which implies $\lambda=0.93 .^{1}$ Anderson and Van Wincoop (2004) review studies that offer gravity-based estimates for the trade elasticity all within the range of -5 and -10 . Applying the previous formula for the United States implies welfare gains from trade ranging from $0.7 \%$ to $1.4 \%$.

Section 2 offers a first look at the theoretical relationship between trade and welfare by focusing on the simplest trade model possible: the Armington model. This model has played a

\footnotetext{
${ }^{1}$ Import penetration ratios are calculated from the OECD Input-Output Database: 2006 Edition as imports over gross output (rather than GDP), so that they can be interpreted as a share of (gross) total expenditures allocated to imports (see Norihiko and Ahmad (2006)).
} 
central role in the gravity literature; see e.g. Anderson (1979) and Anderson and Van Wincoop (2003). It is based on the simplifying assumption that goods are "differentiated by country of origin": no two countries can produce the same good and each good enters preferences in a Dixit-Stiglitz fashion. In this simple environment, the logic behind our welfare formula is straightforward. On the one hand, changes in real income depend on terms-of-trade changes. On the other hand, terms-of-trade changes vis a vis each trade partner can be inferred from changes in relative imports using the trade elasticity, which is just equal to one minus the elasticity of substitution across goods. Aggregating changes in relative imports across all exporters, we immediately obtain Equation (1).

Section 3 describes our general results and the class of models to which they apply. The trade models that we focus on feature four primitive assumptions: ( $i$ ) Dixit-Stiglitz preferences; (ii) one factor of production; (iii) linear cost functions; and (iv) perfect or monopolistic competition; as well as three macro-level restrictions: $(i)$ trade is balanced; $(i i)$ aggregate profits are a constant share of aggregate revenues; and (iii) "the import demand system is CES". ${ }^{2}$ Although these assumptions are admittedly restrictive, they are satisfied in many well-known trade models besides the Armington model, such as Eaton and Kortum (2002), Krugman (1980), and multiple variations and extensions of Melitz (2003) featuring Pareto distributions of firm-level productivity. Given the importance of the previous class of models for quantitative analysis, we refer to them as "quantitative trade models" in the rest of this paper.

Quantitative trade models differ substantially in terms of their margins of adjustment to foreign shocks. In the Armington model all adjustments take place on the consumption side, while in other models adjustments also take place through labor reallocations across sectors, across firms within sectors, or even across products within firms. In turn, these different models lead to different micro-level predictions, different sources of gains from trade, and different structural interpretations of the trade elasticity. Yet, conditional on the observed changes in the share of domestic expenditure and an estimate of the trade elasticity, our general results show that their welfare predictions remain the same: changes in real income caused by foreign shocks are given by Equation (1). ${ }^{3}$

\footnotetext{
${ }^{2}$ The restriction that the "import demand system is CES" is analogous, but distinct from the more standard assumption that the demand system is CES. We provide a formal definition in Section 3.

${ }^{3}$ Given the class of models that we consider, we use, without risk of confusion, the terms real income and welfare interchangeably throughout the paper.
} 
Of course, our welfare formula is only useful if we have observed $\widehat{\lambda}$ (or if we are only interested in movements to autarky for which we know that $\widehat{\lambda}=1 / \lambda)$. Thus, it is useful to compute the welfare consequences of past episodes of trade liberalization, but not necessarily to forecast the consequences of future episodes, as different trade models satisfying our assumptions could, in principle, predict different changes in the share of domestic expenditure. Our last formal result, however, demonstrates that if one imposes a stronger version of our CES restriction on the import demand system, then the predicted changes in the share of domestic expenditure associated with any foreign shock to variable trade costs must also be equal across different models, thereby providing a stronger equivalence result for this subclass of models. ${ }^{4}$

Section 4 explains why our welfare formula arises (or not) in two specific environments: the Ricardian model and the Melitz (2003) model. In both examples we first describe how, using our three macro-level restrictions, one can infer changes in real income from changes in aggregate trade flows alone, thereby leading to the same welfare formula as in a simple Armington model. We then explore the conditions under which our macro-level restrictions hold in each environment. In the same way that Dixit-Stiglitz preferences are crucial to establish Equation (1) in the Armington model, these restrictions require strong functional form restrictions on the distribution of productivity levels across goods, namely Fréchet under perfect competition or Pareto under monopolistic competition.

Section 5 presents extensions of our general results. Motivated by the existing literature, we focus on environments with multiple sectors and tradable intermediate goods. While our simple welfare formula no longer holds in these richer environments, we demonstrate that generalized versions can easily be derived using the same logic as in the previous sections. Compared to our previous results, the main difference is that the equivalence between trade models with perfect and monopolistic competition may now break down. This breakdown happens if, in the country affected by the foreign shock, there are either changes in the measure of goods that can be produced in different sectors or changes in fixed entry and exporting costs.

Section 6 concludes by discussing how the gravity equation offers a common way to estimate the trade elasticity across different models considered in this paper. Together with this

\footnotetext{
${ }^{4}$ As we later discuss, this strong version of our CES restriction on the import demand system is satisfied, for example, by Krugman (1980), Eaton and Kortum (2002) and Eaton, Kortum and Kramarz (2010). Arkolakis (2010) offers an example of models satisfying the weak, but not the strong version of our CES restriction.
} 
estimate, our welfare formula therefore provides a common estimator of the gains from trade, independently of the micro-level details of the model we use.

Our paper is related to the recent literature in public finance trying to isolate robust insights for welfare analysis across different models; see e.g. Chetty (2009). As in that literature, using a "sufficient statistics approach" allows us to make welfare predictions without having to solve for all endogenous variables in our model. In a field such as international trade where general equilibrium effects are numerous, this represents a significant benefit.

In the international trade literature, there is now a large number of empirical papers focusing on the measurement of the gains from trade; see e.g. Feenstra (1994), Klenow and RodríguezClare (1997), Broda and Weinstein (2006), Feenstra and Kee (2008), Goldberg, Khandelwal, Pavcnik and Topalova (2009), and Feenstra and Weinstein (2009). The purpose of such exercises is to quantify the contribution of a particular margin, e.g., new goods or new products, to changes in real income. The goal of our paper is quite different. We are not trying to establish that a particular margin has small or large welfare effects. Instead, our objective is to demonstrate that for quantitative trade models, whatever the welfare contribution of particular margins may be, the total size of the gains from trade can always be computed using the same aggregate statistics, $\lambda$ and $\varepsilon .^{5}$

From a theoretical standpoint, our paper builds on the seminal contribution of Eaton and Kortum (2002) who first computed real wages as a function of $\lambda$ and $\varepsilon$ in order to quantify the gains from trade in a Ricardian model with Dixit-Stiglitz preferences and productivity levels drawn from a Fréchet distribution. In recent work, Arkolakis, Demidova, Klenow and Rodríguez-Clare (2008) also used closed forms to compute the real wage as a function of $\lambda$ and $\varepsilon$ in a specific variation of Melitz (2003) with fixed exporting costs paid in the importing country and firm productivity levels drawn from a Pareto distribution. Noting that the expression was similar to the one derived by Eaton and Kortum (2002) - and could have been derived by Krugman (1980) - Arkolakis et al. (2008) argued that the gains from trade in these models were the same. ${ }^{6}$

\footnotetext{
${ }^{5}$ Accordingly, it should be clear that previous empirical results which have quantified the welfare effects of particular margins neither support nor contradict our equivalence results.

${ }^{6}$ In a recent paper, Feenstra (2009) uses duality theory to revisit, among other things, the results of Arkolakis et al. (2008). Under the same functional form assumptions, he shows how the gains from trade in the Melitz (2003) model computed by Arkolakis et al. (2008) can be interpreted as "production gains" from trade, whereas the gains from trade in Krugman (1980) can be interpreted as "consumption gains." However, he does not
} 
The main difference between Arkolakis et al. (2008) and our paper is in terms of scope and method. In terms of scope, the model for which analytical results were derived in Arkolakis et al. (2008) is only one particular example of models covered in our paper. In Section 3, we allow for perfect competition, monopolistic competition with free and restricted entry, heterogeneity in fixed exporting costs across firms, fixed exporting costs paid in both the importing and exporting country, and endogenous technological decisions. In addition, our general results not only demonstrate that welfare changes are the same given changes in $\lambda$ and $\varepsilon$, but that predicted changes in $\lambda$ themselves may be the same across different models. Just as importantly, in terms of method, Arkolakis et al. (2008) focus on the algebra of their parametrized example, pointing out that similar closed-form expressions hold in different models, but leaving unexplained the reason why they do. Instead, by identifying the macro-level restrictions upon which Equation (1) relies, our analysis is able to offer a unifying perspective on the welfare predictions of models under different market structures, to isolate the economic mechanisms at play, and therefore, to clarify the origins of the equivalence between these models.

Another related paper is Atkeson and Burstein (2010), which focuses on the welfare gains from trade liberalization through its effects on entry and exit of firms and their incentives to innovate in a monopolistically competitive environment with symmetric countries as in Melitz (2003). At the theoretical level, they show that if small changes in trade costs are symmetric, then their impact on welfare must be the same as in Krugman (1980). While their analytical results and ours have the same flavor, the logic is quite different. Their results consist in showing that in this environment, the overall contribution of "new" margins, i.e. any margins not already present in Krugman (1980), must be offset, to a first-order approximation, by changes in entry. By contrast, this offsetting effect is (generically) absent from the models with monopolistic competition considered in our paper. Our results simply state that whatever the welfare effects associated with these new margins are, the total size of the gains from trade can still be inferred from aggregate trade flows alone.

discuss the fact that conditional on $\lambda$ and $\varepsilon$, the total size of the gains from trade predicted by these two models is the same. This is our main focus. 


\section{A First Look at Trade and Welfare}

In order to illustrate the logic of our main result, we first focus on the simplest trade model possible: the Armington model. On the supply side, the Armington model is isomorphic to an endowment model. There are $i=1, \ldots, n$ countries, each producing a differentiated good one-to-one from labor. The supply of labor is inelastic and given by $L_{i}$. On the demand side, there is a representative agent in each country maximizing the following Dixit-Stiglitz utility function,

$$
U_{i}=\left[\sum_{i=1}^{n} q_{i j}^{(\sigma-1) / \sigma}\right]^{\sigma /(\sigma-1)},
$$

where $q_{i j}$ is the quantity of country $j$ 's good consumed by country $i$ and $\sigma>1$ is the elasticity of substitution between goods. The associated price index in country $j$ is given by

$$
P_{j}=\left[\sum_{i=1}^{n}\left(w_{i} \tau_{i j}\right)^{1-\sigma}\right]^{\frac{1}{1-\sigma}}
$$

where $w_{i}>0$ is the wage in country $i$ and $\tau_{i j} \geq 1$ are the variable (iceberg) trade costs between country $i$ and country $j$. Accordingly, the value $X_{i j}$ of country $j$ 's total imports from country $i$ is equal to

$$
X_{i j}=\left(\frac{w_{i} \tau_{i j}}{P_{j}}\right)^{1-\sigma} Y_{j}
$$

where $Y_{j} \equiv \sum_{i=1}^{n} X_{i j}$ is total expenditure in country $j$ and $1-\sigma<0$ is the partial elasticity of relative imports with respect to variable trade $\operatorname{costs}, \frac{\partial \ln \left(X_{i j} / X_{j j}\right)}{\partial \ln \tau_{i j}}$, which we referred to as the trade elasticity in the Introduction. Finally, trade balance implies $Y_{j}=w_{j} L_{j}$.

Now consider a foreign shock in country $j$ that affects labor endowments, $\boldsymbol{L} \equiv\left\{L_{i}\right\}$, and trade costs, $\boldsymbol{\tau} \equiv\left\{\tau_{i j}\right\}$, around the world, but leaves unchanged country $j$ 's labor endowment, $L_{j}$, as well as its ability to serve its own market, $\tau_{j j}$. What is the change in real income, $W_{j} \equiv Y_{j} / P_{j}$, caused by such a shock? Answering this question in the context of the Armington model is straightforward. Using labor in country $j$ as our numeraire, and noting that trade balance implies $d \ln Y_{j}=d \ln w_{j}$, we have $d \ln Y_{j}=0$. By Equations (2) and (3), changes in real income are therefore given by

$$
d \ln W_{j}=-\sum_{i=1}^{n} \lambda_{i j}\left(d \ln w_{i}+d \ln \tau_{i j}\right),
$$


where $\lambda_{i j} \equiv X_{i j} / Y_{j}$ is the share of country $j$ 's total expenditure that is devoted to goods from country $i$. By Equation (3), changes in relative imports are such that

$$
d \ln \lambda_{i j}-d \ln \lambda_{j j}=(1-\sigma)\left(d \ln w_{i}+d \ln \tau_{i j}\right)
$$

Combining Equations (4) and (5), we obtain

$$
d \ln W_{j}=\frac{\sum_{i=1}^{n} \lambda_{i j}\left(d \ln \lambda_{j j}-d \ln \lambda_{i j}\right)}{1-\sigma}=\frac{d \ln \lambda_{j j}}{1-\sigma}
$$

where the second equality derives from the fact that $\sum_{i=1}^{n} \lambda_{i j}=1$. Integrating the previous expression between the initial equilibrium (before the shock) and the new equilibrium (after the shock), we finally get

$$
\widehat{W}_{j}=\widehat{\lambda}_{j j}^{1 /(1-\sigma)}
$$

where $\widehat{v} \equiv v^{\prime} / v$ denotes the change in any variable $v$ between the initial and the new equilibrium. Equation (6) will be at the core of our analysis. It shows that welfare changes in country $j-$ whatever the origin of the foreign shock may be - can be inferred from changes in the share of domestic expenditure, $\lambda_{j j}$, using the trade elasticity, here $1-\sigma$.

The basic idea behind Equation (6) should be clear. On the one hand, welfare changes in country $j$ only depends on terms-of-trade changes (Equation 4). On the other hand, termsof-trade changes can be inferred from changes in the relative demand for goods from different countries (Equation 5). In the next sections, we will consider models with more margins of adjustment than a simple Armington model. In particular, such models will be characterized by the fact that changes in trade costs also affect the set of goods being exported by different countries. Yet, by invoking a few key macro-level restrictions that trivially hold in the Armington model, the same basic logic will apply, and so will our welfare formula.

\section{General Results}

We start by describing our primitive assumptions on preferences, technology, and market structure. We then introduce reduced-form macro-level restrictions and demonstrate how any trade model that satisfies the previous conditions must have, in some well-defined sense, the same 
welfare predictions. Specific examples will be discussed in detail in Section 4.

\subsection{Preferences, Technology, and Market Structure}

We consider a world economy comprising $i=1, \ldots, n$ countries; one factor of production, labor; and multiple goods indexed by $\omega \in \Omega$. We denote by $\bar{N}$ the measure of goods in $\Omega{ }^{7}$ Labor is inelastically supplied and immobile across countries. $L_{i}$ and $w_{i}$ denote the total endowment of labor and the wage in country $i$, respectively.

Preferences. In each country $i$, there is a representative agent with Dixit-Stiglitz preferences maximizing her utility subject to her budget constraint. The associated price index is given by

$$
P_{i}=\left(\int_{\omega \in \Omega} p_{i}(\omega)^{1-\sigma} d \omega\right)^{\frac{1}{1-\sigma}}
$$

where $p_{i}(\omega)$ is the price of good $\omega$ in country $i$ and $\sigma>1$ is the elasticity of substitution between goods. We adopt the convention that $p_{i}(\omega)=+\infty$ if good $\omega$ is not available in country $i$.

Technology. For every good $\omega \in \Omega$, there is a blueprint that can be acquired by one or many firms depending on the market structure (to be described below). For any exporting country $i$ and any importing country $j$, the blueprint associated with good $\omega$ contains a set of destination-specific techniques $t \in T_{i j}$ that can be used to produce the good in country $i$ and sell it to country $j$. If a firm from country $i$ uses techniques $\boldsymbol{t} \equiv\left\{t_{j}\right\}$ to produce quantities $\boldsymbol{q} \equiv\left\{q_{j}\right\}$ of good $\omega$, its cost function is given by

$$
C_{i}(\boldsymbol{w}, \boldsymbol{q}, \boldsymbol{t}, \omega)=\sum_{j=1}^{n}\left[c_{i j}\left(w_{i}, t_{j}, \omega\right) q_{j}+f_{i j}\left(w_{i}, w_{j}, t_{j}, \omega\right) \mathbb{I}\left(q_{j}>0\right)\right]
$$

where $\boldsymbol{w} \equiv\left\{w_{j}\right\}$ is the vector of wages and $\mathbb{I}(\cdot)$ is an indicator function. For each destination country $j, c_{i j}\left(w_{i}, t_{j}, \omega\right)>0$ is the constant marginal cost, which only requires labor in country $i$, and $f_{i j}\left(w_{i}, w_{j}, t_{j}, \omega\right) \geq 0$ is a fixed exporting cost, which may require labor in both the exporting and importing countries. In line with the previous literature, we assume that constant marginal

\footnotetext{
${ }^{7} \Omega$ may include either a discrete or a continuum of goods. Thus whenever the integral sign " $\int_{\omega \in \Omega}$ " appears, one should think of a Lebesgue integral. If $\Omega$ is a finite or countable set, " $\int_{\omega \in \Omega}$ " is simply equivalent to " $\sum_{\omega \in \Omega}$ ". This minor technicality allows us to cover the Armington model presented in Section 2. In practice, however, all other existing quantitative trade models comprise a continuum of goods.
} 
costs and fixed exporting costs can be written as

$$
\begin{aligned}
c_{i j}\left(w_{i}, t_{j}, \omega\right) & \equiv \tau_{i j} \cdot w_{i} \cdot \alpha_{i j}(\omega) \cdot t_{j}^{\frac{1}{1-\sigma}} \\
f_{i j}\left(w_{i}, w_{j}, t_{j}, \omega\right) & \equiv \xi_{i j} \cdot h_{i j}\left(w_{i}, w_{j}\right) \cdot \phi_{i j}(\omega) \cdot m_{i j}\left(t_{j}\right),
\end{aligned}
$$

where $\tau_{i j} \geq 1$ and $\xi_{i j}>0$ are exogenous parameters common to all blueprints, which we will use to parametrize changes in variable and fixed trade costs, respectively; ${ }^{8} h_{i j}\left(w_{i}, w_{j}\right)>0$ is a homogenous of degree one function that captures the importance of domestic and foreign labor in fixed exporting costs; $\alpha_{i j}(\omega)>0$ and $\phi_{i j}(\omega) \geq 0$ reflect the exogenous heterogeneity across blueprints; and $m_{i j}\left(t_{j}\right) \geq 0$ reflects endogenous destination-specific technological decisions. In the rest of this paper, we assume that $T_{i j} \equiv[\underline{t}, \bar{t}]$, with $\underline{t} \geq 0$ and $\bar{t}>0$, and that $m_{i j}$ satisfies $m_{i j}^{\prime}>0$ and $m_{i j}^{\prime \prime}<0$, which will guarantee the existence of a unique profit-maximizing technique for all goods and all destinations. Since $\sigma>1$ and $m_{i j}$ is increasing, higher $t$ techniques imply higher fixed exporting costs, but lower marginal costs. ${ }^{9}$

Market Structure. We consider two market structures: $(i)$ perfect competition and $(i i)$ monopolistic competition (with either restricted or free entry). Under both market structures, there is a large number of firms and all goods and labor markets clear. Under perfect competition, firms have free access to all blueprints; there are no fixed exporting costs, $\phi_{i j}(\omega)=0$ for all $i, j, \omega ;$ and all firms maximize profits taking wages and prices as given.

Under monopolistic competition with restricted entry, we assume that an exogenous measure of firms, $\bar{N}_{i}<\bar{N}$, freely receive monopoly power over a blueprint. Under monopolistic competition with free entry, by contrast, firms from country $i$ need to hire $F_{i}>0$ units of labor in order to acquire monopoly power over a blueprint. ${ }^{10}$ The assignment of blueprints to firms

\footnotetext{
${ }^{8}$ Despite this terminology, it should be clear that changes in variable trade costs may also capture productivity changes: if $\tau_{i j}$ decrease by the same amount for all countries $j=1, \ldots, n$, this is equivalent to an increase in labor productivity in country $i$. Note also that in line with the existing literature, variable trade costs, whatever their origins may be, are modelled as cost- rather than demand-shifters.

${ }^{9} \mathrm{It}$ is worth emphasizing that our assumptions on technology do not impose any restriction on the distribution of unit labor requirements, $\alpha_{i j}(\omega)$, and fixed exporting costs, $\phi_{i j}(\omega)$, across goods. In particular, we allow these distributions to be degenerate. Thus monopolistically competitive models with homogeneous firms, for example, are strictly covered by our analysis.

${ }^{10}$ Under both restricted and free entry, each firm gets monopoly power over only one blueprint. Thus, formally, there are no multi-product firms as in Bernard, Redding and Schott (2009) or Arkolakis and Muendler (2010). Extending our analysis to the case of multi-product firms is trivial if there are no fixed trade costs at the firmlevel. Otherwise, our formal results would remain valid, but one would need to reinterpret the choice of which products to sell in a particular destination as another destination-specific endogenous technological decision.
} 
is random. The measure of goods $N_{i}$ that can be produced in country $i$ is then endogenously determined so that entry costs, $w_{i} F_{i}$, are equal to expected profits. Under both restricted and free entry, we assume that once assigned a blueprint, firms maximize profits taking wages, total expenditure, and consumer price indexes as given.

\subsection{Macro-level Restrictions}

We restrict ourselves to trade models satisfying three macro-level restrictions: $(i)$ trade is balanced; (ii) aggregate profits are a constant share of GDP; and (iii) the "import demand system is CES". We now describe each restriction in detail.

Trade is balanced. As in Section 2 , let $X_{i j}$ denote the total value of country $j$ 's imports from country $i$ and let $\mathbf{X} \equiv\left\{X_{i j}\right\}$ denote the $n \times n$ matrix of bilateral imports. Bilateral imports can be expressed as

$$
X_{i j}=\int_{\omega \in \Omega_{i j}} x_{i j}(\omega) d \omega,
$$

where $\Omega_{i j} \subset \Omega$ is the set of goods that country $j$ buys from country $i$ and $x_{i j}(\omega)$ is the value of country $j$ 's imports of good $\omega$ from country $i$. Our first macro-level restriction is that the value of imports must be equal to the value of exports:

R1 For any country $j, \sum_{i=1}^{n} X_{i j}=\sum_{i=1}^{n} X_{j i}$.

If fixed exporting costs are only paid in labor of the exporting country, R1 directly derives from the budget constraint of country $j$ 's representative agent. In general, however, total income of the representative agent in country $j$ may also depend on the wages paid to foreign workers by country $j$ 's firms as well as the wages paid by foreign firms to country $j$ 's workers. Thus, total expenditure in country $j, Y_{j} \equiv \sum_{i=1}^{n} X_{i j}$, could be different from country $j$ 's total revenues,

$R_{j} \equiv \sum_{i=1}^{n} X_{j i}$. R1 rules out this possibility. As in Section 2 , we denote by $\lambda_{i j} \equiv X_{i j} / Y_{j}$ the share of country $j$ 's total expenditure that is devoted to goods from country $i$.

Aggregate profits are a constant share of revenues. Let $\Pi_{j}$ denote country $j$ 's aggregate profits gross of entry costs (if any). Our second macro-level restriction states that $\Pi_{j}$ must be a constant share of country $j$ 's total revenues:

$\mathbf{R 2}$ For any country $j, \Pi_{j} / R_{j}$ is constant. 
Under perfect competition, R2 trivially holds since aggregate profits are equal to zero. Under monopolistic competition with homogeneous firms, R2 also necessarily holds because of DixitStiglitz preferences; see Krugman (1980). In more general environments, however, R2 is a non-trivial restriction. We come back to this issue in Section 4.

The import demand system is CES. Our last macro-level restriction is concerned with the partial equilibrium effects of variable trade costs on aggregate trade flows. As we later discuss in Section 6 , these are precisely the effects that can be recovered from a simple gravity equation. To introduce this last restriction formally, we define the import demand system as the mapping from $(\boldsymbol{w}, \boldsymbol{N}, \boldsymbol{\tau})$ into $\boldsymbol{X} \equiv\left\{X_{i j}\right\}$, where $\boldsymbol{w} \equiv\left\{w_{i}\right\}$ is the vector of wages, $\boldsymbol{N} \equiv\left\{N_{i}\right\}$ is the vector of measures of goods that can be produced in each country, and $\boldsymbol{\tau} \equiv\left\{\tau_{i j}\right\}$ is the matrix of variable trade costs. This mapping is determined by utility and profit maximization given preferences, technological constraints, and market structure. ${ }^{11}$ It excludes, however, labor market clearing conditions as well as free entry conditions (if any) which determine the equilibrium values of $\boldsymbol{w}$ and $\boldsymbol{N}$. Broadly speaking, one can think of an import demand system as a set of labor demand curves whose properties will be used to infer how changes in trade costs affect the relative demand for labor in different countries. Our third macro-level restriction imposes restrictions on the partial elasticities, $\varepsilon_{j}^{i i^{\prime}} \equiv \partial \ln \left(X_{i j} / X_{j j}\right) / \partial \ln \tau_{i^{\prime} j}$, of that system:

R3 The import demand system is such that for any importer $j$ and any pair of exporters $i \neq j$ and $i^{\prime} \neq j, \varepsilon_{j}^{i{ }^{\prime}}=\varepsilon<0$ if $i=i^{\prime}$, and zero otherwise.

Each elasticity $\varepsilon_{j}^{i i^{\prime}}$ captures the percentage change in the relative imports from country $i$ in country $j$ associated with a change in the variable trade costs between country $i^{\prime}$ and $j$ holding wages and the measure of goods that can be produced in each country fixed. According to R3, like in a simple Armington model, any given change in bilateral trade costs, $\tau_{i j}$, must have a symmetric impact on relative demand, $X_{i j} / X_{j j}$, for all exporters $i \neq j$. In addition, any change in a third country trade costs, $\tau_{i^{\prime} j}$, must have the same proportional impact on $X_{i j}$ and $X_{j j}$. Thus, changes in relative demand are separable across exporters: changes in the relative

\footnotetext{
${ }^{11}$ In principle, these equilibrium conditions may lead to multiple values of $\boldsymbol{X}$ for a given value of $(\boldsymbol{w}, \boldsymbol{N}, \boldsymbol{\tau})$ if firms from different countries have the same costs of producing and delivering a positive measure of goods to the same destination under perfect competition or if a positive measure of firms earn zero profits (gross of entry costs) under monopolistic competition. Both knife-edge scenarios, however, will be ruled out under our third-macro level restriction. At this point, if there are multiple values of $\boldsymbol{X}$, we arbitrarily select one, the choice of the tie-breaking rule being of no consequence for the rest of our analysis.
} 
demand for goods from country $i, X_{i j} / X_{j j}$ only depends on changes in $\tau_{i j}$. When R3 is satisfied we say that the import demand system is $C E S$ and refer to $\varepsilon$ as the trade elasticity of that system. ${ }^{12}$

A few comments are in order. First, the trade elasticity $\varepsilon$ is an upper-level elasticity: it summarizes how changes in variable trade costs affect aggregate trade flows, whatever the particular margins of adjustment, $x_{i j}(\omega)$ or $\Omega_{i j}$, may be. Below we will refer to the margin of adjustment for trade flows associated with $x_{i j}(\omega)$ as the "intensive margin" and to the margin of adjustment associated with $\Omega_{i j}$ as the "extensive margin". Second, R3 is a global restriction in that it requires the trade elasticity to be constant across all equilibria. ${ }^{13}$ Third, under perfect competition, R3 implies complete specialization in the sense that for all $i, i^{\prime} \neq i$, and $j$, the measure of goods in $\Omega_{i j} \cap \Omega_{i^{\prime} j}$ must be equal to zero. Similarly, under monopolistic competition, R3 implies that the measure of firms that are indifferent about selling in a particular market must be equal to zero. If these conditions were not true, at least one partial elasticity $\varepsilon_{j}^{i i^{\prime}}$ would be equal to $+\infty$. Finally, it is worth pointing out that although restrictions R1-R3 play a distinct role in our analysis, they are not necessarily independent from one another. As we have shown formally in the working paper version of this paper, Arkolakis, Costinot and Rodríguez-Clare (2009), R3 implies R2 if fixed trade costs are only paid in labor of the exporting country.

In the rest of the paper we refer to models that satisfy the primitive assumptions introduced in Section 3.1 as well as the macro-level restrictions R1-R3 as "quantitative trade models."

For some of our results, we will use a stronger version of restriction R3:

R3' The import demand system is such that for any exporter $i$ and importer $j$,

$$
X_{i j}=\frac{\chi_{i j} \cdot N_{i} \cdot\left(w_{i} \tau_{i j}\right)^{\varepsilon} \cdot Y_{j}}{\sum_{i^{\prime}=1}^{n} \chi_{i^{\prime} j} \cdot N_{i^{\prime}} \cdot\left(w_{i^{\prime}} \tau_{i^{\prime} j}\right)^{\varepsilon}},
$$

\footnotetext{
${ }^{12}$ Our choice of terminology derives from the fact that in the case of a CES demand system, changes in relative demand, $C_{k} / C_{l}$, for two goods $k$ and $l$ are such that $\partial \ln \left(C_{k} / C_{l}\right) / \partial \ln p_{k^{\prime}}=0$ if $k^{\prime} \neq k, l$ and $\partial \ln \left(C_{k} / C_{l}\right) / \partial \ln p_{k}=\partial \ln \left(C_{k^{\prime}} / C_{l}\right) / \partial \ln p_{k^{\prime}} \neq 0$ for all $k, k^{\prime} \neq l$. Nevertheless, it should be clear that the assumption of a CES import demand system is conceptually distinct from the assumption of CES preferences. While the import demand obviously depends on preferences, it also takes into account the supply side as this affects the allocation of expenditures to domestic production. In fact, CES preferences are neither necessary nor sufficient to obtain a CES import demand system.

${ }^{13}$ This aspect of R3 is only necessary for our results to the extent that we are interested in the welfare evaluation of arbitrary foreign shocks. A local version of R3 (i.e., assuming that R3 only holds at the initial equilibrium) would be sufficient to obtain a local version of our main result (i.e., one in which we characterize welfare changes in response to infinitesimally small shocks). We come back to this issue in Section 4 .
} 
where $\chi_{i j}$ is a function of, and only of, structural parameters distinct from $\boldsymbol{\tau}$.

While R3' implies the same restriction on the partial elasticities $\varepsilon_{j}^{i{ }^{\prime}}$ as R3, it further provides a structural relationship between bilateral imports, wages, and the measure of goods that can be produced in each country which we will exploit to predict changes in trade flows.

\subsection{Welfare valuation}

We are interested in evaluating the changes in real income, $W_{j} \equiv Y_{j} / P_{j}$, associated with foreign shocks in country $j$. To do so, we first introduce the following formal definition.

Definition 1 A foreign shock in country $j$ is a change from $(\boldsymbol{L}, \boldsymbol{F}, \boldsymbol{\tau}, \boldsymbol{\xi})$ to $\left(\boldsymbol{L}^{\prime}, \boldsymbol{F}^{\prime}, \boldsymbol{\tau}^{\prime}, \boldsymbol{\xi}^{\prime}\right)$ such that $L_{j}=L_{j}^{\prime}, F_{j}=F_{j}^{\prime}, \tau_{j j}=\tau_{j j}^{\prime}, \xi_{j j}=\xi_{j j}^{\prime}$, with $\boldsymbol{L} \equiv\left\{L_{i}\right\}, \boldsymbol{F} \equiv\left\{F_{i}\right\}, \boldsymbol{\tau} \equiv\left\{\tau_{i j}\right\}$, and $\boldsymbol{\xi} \equiv\left\{\xi_{i j}\right\}$.

Put simply, foreign shocks correspond to any changes in labor endowments, entry costs, variable trade costs, and fixed trade costs that do not affect either country $j$ 's endowment or its ability to serve its own market.

Ex post welfare evaluation. We are now ready to state our first welfare prediction.

Proposition 1 Suppose that Restrictions R1-R3 hold. Then the change in real income associated with any foreign shock in country $j$ can be computed as

$$
\widehat{W}_{j}=\widehat{\lambda}_{j j}^{1 / \varepsilon}
$$

Proposition 1 offers a parsimonious way to evaluate welfare changes resulting from foreign shocks. One does not need to know the origins of the foreign shock or the way in which it affects trade flows from different countries; it is sufficient to have information about the trade elasticity, $\varepsilon$, and the changes in trade flows as summarized by $\widehat{\lambda}_{j j}$.

It is worth emphasizing that Proposition 1 is an ex post result in the sense that the percentage change in real income is expressed as a function of the change in the share of domestic expenditure. Thus, it is only useful to the extent that $\widehat{\lambda}_{j j}$ is observed. For instance, looking at historical trade data, Proposition 1 can be used to infer the welfare consequences of past episodes of trade liberalization. However, it cannot be used to forecast the welfare consequences 
of future episodes of trade liberalization, as different trade models satisfying Restrictions R1R3 may, in principle, predict different changes in the share of domestic expenditure for a given foreign shock.

Ex ante welfare evaluation. We now turn to a very particular, but important type of shock: moving to autarky. Formally, we assume that variable trade costs in the new equilibrium are such that $\tau_{i j}^{\prime}=+\infty$ for any pair of countries $i \neq j$. All other technological parameters and endowments are the same as in the initial equilibrium. For this particular counterfactual exercise, any trade model must predict the same change in the share of domestic expenditure: $\hat{\lambda}_{j j}=1 / \lambda_{j j}$ since $\lambda_{j j}^{\prime}=1$ under autarky. Combining this observation with Proposition 1 , we immediately get:

Corollary 1 Suppose that Restrictions R1-R3 hold. Then the change in real income associated with moving to autarky in country $j$ can be computed as

$$
\widehat{W}_{j}^{A}=\lambda_{j j}^{-1 / \varepsilon}
$$

Unlike Proposition 1, Corollary 1 is an ex ante result in the sense that it does not require any information on trade flows in the new equilibrium. Conditional on initial values of $\lambda_{j j}$ and $\varepsilon$, the gains from trade predicted by all models satisfying Restrictions R1-R3 must be the same. Within that class of models, new margins of adjustment may affect the structural interpretation of the trade elasticity, and in turn, the composition of the gains from trade. Nevertheless, new margins cannot change the total size of the gains from trade. The absolute value of the percentage change in real income associated with moving from the initial equilibrium to autarky remains given by $1-\lambda^{-1 / \varepsilon}$, as stated in the Introduction.

Ex-ante results can be derived for any change in variable trade costs if one strengthens our third macro-level restriction from R3 to R3'.

Proposition 2 Suppose that Restrictions R1-R3' hold. Then the percentage change in real income associated with any change in variable trade costs in country $j$ can be computed using Equation (9) combined with

$$
\widehat{\lambda}_{j j}=\frac{1}{\sum_{i=1}^{n} \lambda_{i j}\left(\hat{w}_{i} \hat{\tau}_{i j}\right)^{\varepsilon}},
$$


where $\hat{w}_{j}=1$ by choice of numeraire, and $\left\{\hat{w}_{i}\right\}_{i \neq j}$ are implicitly given by the solution of

$$
\hat{w}_{i}=\sum_{j^{\prime}=1}^{n} \frac{\lambda_{i j^{\prime}} \hat{w}_{j^{\prime}} Y_{j^{\prime}}\left(\hat{w}_{i} \hat{\tau}_{i j^{\prime}}\right)^{\varepsilon}}{Y_{i} \sum_{i^{\prime}=1}^{n} \lambda_{i^{\prime} j^{\prime}}\left(\hat{w}_{i^{\prime}} \hat{\tau}_{i^{\prime} j^{\prime}}\right)^{\varepsilon}} .
$$

Since Equations (11) and (12) only depend on trade data and the trade elasticity, Proposition 2 implies that the welfare consequences of any change in variable trade costs, not just moving to autarky, must be the same in all trade models satisfying Restrictions R1-R3'. ${ }^{14}$

\section{Examples}

The main features of the trade models analyzed in Section 3 include four primitive assumptions: (i) Dixit-Stiglitz preferences; (ii) one factor of production; (iii) linear cost functions; and $(i v)$ perfect or monopolistic competition; as well as three macro-level restrictions, which trivially hold in a simple Armington model: $(i)$ trade is balanced; $(i i)$ aggregate profits are a constant share of aggregate revenues; and $(i i i)$ the import demand system is CES. In order to illustrate the logic of our general results we now highlight two simple examples that satisfy our primitive assumptions, but may or may not satisfy our macro-level restrictions: the Ricardian model and the Melitz (2003) model. ${ }^{15}$ We first demonstrate how, like in a simple Armington model, one can go from aggregate trade flows to welfare predictions under our three macro-level restrictions. We then discuss the exact role of our macro-level restrictions as well as the conditions under which they hold in each environment.

\subsection{The Ricardian Model}

In this first example, we focus on perfect competition, abstract from endogenous technological choices, $\underline{t}=\bar{t}=1$, and assume that good-specific unit labor requirements do not vary across

\footnotetext{
${ }^{14}$ In the context of the Eaton and Kortum (2002) model, Dekle, Eaton and Kortum (2008) have previously shown that the change in trade flows triggered by an arbitrary shock to variable trade costs can be entirely characterized in terms of the trade elasticity and the initial equilibrium trade flows. The proof of the Proposition builds on Dekle, Eaton and Kortum (2008) approach and demonstrates that their result generalizes to any quantitative trade model satisfying R1-R3'.

${ }^{15}$ Whereas we do not focus on Krugman (1980) in this section, it should be clear that it satisfies our four primitive assumptions as well as our three macro-level restrictions. In Krugman (1980), we simply have a degenerate distribution of unit labor requirements and fixed trade costs; R1 trivially holds in the absence of fixed exporting costs; and R2, R3 and R3' are direct implications of Dixit-Stiglitz preferences. Accordingly, Krugman (1980) leads to the same welfare predictions as a simple Armington model.
} 
destinations, $\alpha_{i j}(\omega) \equiv \alpha_{i}(\omega)$. Under these assumptions, the general model presented in Section 3 reduces to a Ricardian model. Throughout this example, we denote by $G\left(\alpha_{1}, \ldots, \alpha_{n}\right)$ the share of goods $\omega \in \Omega$ such that $\alpha_{i}(\omega) \leq \alpha_{i}$ for all $i$, and by $g\left(\alpha_{1}, \ldots, \alpha_{n}\right)$ the associated density function.

Aggregate trade flows. Under perfect competition, the set of goods $\Omega_{i j}$ that country $j$ buys from country $i$ is given by

$$
\Omega_{i j}=\left\{\omega \in \Omega \mid c_{i j} \alpha_{i j}(\omega)<c_{i^{\prime} j} \alpha_{i^{\prime} j}(\omega) \text { for all } i^{\prime} \neq i\right\}
$$

where $c_{i j} \equiv w_{i} \tau_{i j}$. Combining this observation with Dixit-Stiglitz preferences, we can write aggregate trade flows as

$$
X_{i j}=\frac{\int_{0}^{+\infty}\left(c_{i j} \alpha_{i}\right)^{1-\sigma} g_{i}\left(\alpha_{i}, c_{1 j}, \ldots, c_{n j}\right) d \alpha_{i}}{\sum_{i^{\prime}=1}^{n} \int_{0}^{+\infty}\left(c_{i^{\prime} j} \alpha_{i^{\prime}}\right)^{1-\sigma} g_{i^{\prime}}\left(\alpha_{i^{\prime}}, c_{1 j}, \ldots, c_{n j}\right) d \alpha_{i^{\prime}}} Y_{j}
$$

where $g_{i}\left(\alpha_{i}, c_{1 j}, \ldots, c_{n j}\right)$ is the density of goods with unit labor requirements $\alpha_{i}$ in $\Omega_{i j}{ }^{16}$ Accordingly, for any importer $j$ and any pair of exporters $i \neq j$ and $i^{\prime} \neq j$, the import demand system of a Ricardian model satisfies

$$
\frac{\partial \ln \left(X_{i j} / X_{j j}\right)}{\partial \ln \tau_{i^{\prime} j}} \equiv \varepsilon_{j}^{i i^{\prime}}= \begin{cases}1-\sigma+\gamma_{i j}^{i}-\gamma_{j j}^{i} & \text { for } i^{\prime}=i \\ \gamma_{i j}^{i^{\prime}}-\gamma_{j j}^{i^{\prime}} & \text { for } i^{\prime} \neq i\end{cases}
$$

where $1-\sigma$ and $\gamma_{i j}^{i^{\prime}} \equiv \partial \ln \left[\int_{0}^{+\infty} \alpha_{i}^{1-\sigma} g_{i}\left(\alpha_{i}, c_{1 j}, \ldots, c_{n j}\right) d \alpha_{i}\right] / \partial \ln c_{i^{\prime} j}$ are the intensive and extensive margin elasticities, respectively.

Welfare predictions. Let us now demonstrate how the logic behind our welfare formula carries over from the Armington to the Ricardian model. First, note that labor market clearing and the budget constraint of the representative agent imply $d \ln Y_{j}=d \ln w_{j}=0$, where the second equality derives from the choice of labor in country $j$ as our numeraire. Thus, just as in the Armington model, small changes in real income are given by

$$
d \ln W_{j}=-d \ln P_{j}=-\sum_{i=1}^{n} \lambda_{i j} d \ln c_{i j} .
$$

\footnotetext{
${ }^{16}$ Formally, $g_{i}\left(\alpha_{i}, c_{1 j}, \ldots, c_{n j}\right) \equiv \int_{\alpha_{1}>\alpha_{i}} c_{i j} / c_{1 j} \ldots \int_{\alpha_{i-1}>\alpha_{i} c_{i j} / c_{i-1 j}} \int_{\alpha_{i+1}>\alpha_{i} c_{i j} / c_{i+1 j}} \ldots \int_{\alpha_{n}>\alpha_{i} c_{i j} / c_{n j}} g(\boldsymbol{\alpha}) d \boldsymbol{\alpha}-i$, where $\boldsymbol{\alpha} \equiv\left(\alpha_{1}, \ldots, \alpha_{n}\right)$ and $\boldsymbol{\alpha}_{-i}$ denotes the previous vector with the $i$-th component removed.
} 
The second equality reflects the fact that under perfect competition, the welfare effect of changes at the extensive margin is necessarily second-order since consumers must be initially indifferent between the "cutoff" goods produced by different countries. By contrast, changes in trade flows now depend on changes in $\Omega_{i j}$, and hence, the extensive margin elasticities, $\gamma_{i j}^{i^{\prime}}$. In a Ricardian model, by Equation (14), we have

$$
d \ln \lambda_{i j}-d \ln \lambda_{j j}=\left(1-\sigma+\gamma_{i j}^{i}-\gamma_{j j}^{i}\right) d \ln c_{i j}+\sum_{i^{\prime} \neq i, j}^{n}\left(\gamma_{i j}^{i^{\prime}}-\gamma_{j j}^{i^{\prime}}\right) d \ln c_{i^{\prime} j}
$$

Combining the two previous expressions we get

$$
d \ln W_{j}=-\sum_{i=1}^{n} \lambda_{i j}\left[\frac{d \ln \lambda_{i j}-d \ln \lambda_{j j}}{1-\sigma+\gamma_{i j}^{i}-\gamma_{j j}^{i}}-\sum_{i^{\prime} \neq i, j}^{n}\left(\frac{\gamma_{i j}^{i^{\prime}}-\gamma_{j j}^{i^{\prime}}}{1-\sigma+\gamma_{i j}^{i}-\gamma_{j j}^{i}}\right) d \ln c_{i^{\prime} j}\right]
$$

To derive Proposition 1, we then simply note that Equation (15) and R3 imply $\gamma_{i j}^{i^{\prime}}=\gamma_{j j}^{i^{\prime}}$ for all $i^{\prime} \neq i, j$ and $1-\sigma+\gamma_{i j}^{i}-\gamma_{j j}^{i}=\varepsilon$ for all $i \neq j$. Together with $\sum_{i=1}^{n} \lambda_{i j}=1$, Equation (16) therefore implies $d \ln W_{j}=d \ln \lambda_{j j} / \varepsilon$, which can be integrated to get $\widehat{W}_{j}=\widehat{\lambda}_{j j}^{1 / \varepsilon}$.

What is the role of our macro-level restrictions? R1 and R2 are trivially satisfied under perfect competition and do not play any active role in this environment. R3 is the crucial restriction which guarantees that, as in a simple Armington model: $(i)$ changes in each component of the consumer price index, $d \ln c_{i j}$, can be inferred one-by-one from changes in relative imports, $d \ln \lambda_{i j}-d \ln \lambda_{j j}$ (because $\gamma_{i j}^{i^{\prime}}=\gamma_{j j}^{i^{\prime}}$ for all $i^{\prime} \neq i, j$ ); $(i i)$ changes in relative imports can be aggregated into changes in the domestic share of expenditure, $-d \ln \lambda_{j j}$ (because $1-\sigma+\gamma_{i j}^{i}-\gamma_{j j}^{i}=\varepsilon$ for all $i \neq j$ ); and ( $\left.i i i\right)$ small changes in the share of domestic expenditures can be integrated into large ones (because the trade elasticity $\varepsilon$ is constant across equilibria).

The previous conditions are obviously strong. For instance, for condition $(i)$ to hold, it must be the case that third-country changes have symmetric effects on country $i$ and $j$, i.e. $\gamma_{i j}^{i^{\prime}}=\gamma_{j j}^{i^{\prime}}$ for all $i^{\prime} \neq i, j$. Thus R3 rules out, for example, a situation in which a decrease in bilateral trade costs between Costa Rica and the United States has a differential impact on Mexican and Canadian exports to the United States. In the Armington model presented in Section 2, the previous conditions were a direct implication of strong restrictions on the demand-side, namely Dixit-Stiglitz preferences. For the same conditions to hold more generally in a Ricardian model, we will need equally strong restrictions on the supply-side, as we now discuss. 
When are our macro-level restrictions satisfied? As Equation (15) shows, the import demand system may not, in general, satisfy R3 because of the extensive margin elasticities, $\gamma_{i j}^{i^{\prime}}$. Eaton and Kortum's (2002) well-known paper provides an example of a Ricardian model satisfying R3. This model obtains as a particular case of our general model by assuming that $1 / \alpha_{i}(\omega)$ are independently drawn from Fréchet distributions, i.e.

$$
g\left(\alpha_{1}, \ldots, \alpha_{n}\right) \equiv \prod_{i=1}^{n} \theta T_{i} \alpha_{i}^{\theta-1} e^{-T_{i} \alpha_{i}^{\theta}}, \text { for all } \alpha_{1}, \ldots, \alpha_{n} \geq 0
$$

Using the definition of $\gamma_{i j}^{i^{\prime}}$ and differentiating Equation (14), we get $\gamma_{i j}^{i}=-(\theta-\sigma+1) \sum_{i^{\prime} \neq i} \lambda_{i^{\prime} j}$ for $i \neq j$ and $\gamma_{i j}^{i^{\prime}}=(\theta-\sigma+1) \lambda_{i^{\prime} j}$ for $i^{\prime} \neq i, j$. This implies that $\gamma_{i j}^{i^{\prime}}=\gamma_{j j}^{i^{\prime}}=0$ for $i^{\prime} \neq i, j$, whereas $\varepsilon=1-\sigma+\gamma_{i j}^{i}-\gamma_{j j}^{i}=-\theta$ for $i \neq j$ and thus R3 is satisfied. Moreover, combining Equations (17) and (14), we obtain

$$
X_{i j}=\frac{T_{i}\left(w_{i} \tau_{i j}\right)^{-\theta}}{\sum_{i^{\prime}=1}^{n} T_{i^{\prime}}\left(w_{i^{\prime}} \tau_{i^{\prime} j}\right)^{-\theta}} Y_{j}
$$

Thus R3' is satisfied as well. Accordingly, the welfare consequences of any change in variable trade costs, not just moving to autarky, must be the same in Eaton and Kortum (2002) as in a simple Armington model.

The comparison of these two models illustrates the main point of our paper in a very clear manner. Since Eaton and Kortum (2002) entails production gains from trade whereas an Armington model does not, one may think that the gains from trade predicted by Eaton and Kortum (2002) must be larger. Our analysis demonstrates that this is not the case. As we switch from an Armington model to Eaton and Kortum (2002), the structural interpretation of the trade elasticity changes from a preference parameter, $1-\sigma$, to a technological parameter, $-\theta$, reflecting the fact there is now one more margin, namely $\Omega_{i j}$, for bilateral imports to adjust. ${ }^{17}$ Yet, conditional on $\lambda_{j j}$ and $\varepsilon$, more margins of adjustment only affect the composition of the

\footnotetext{
${ }^{17}$ While this is not the focus of our analysis, it is worth mentioning that the trade elasticity in Eaton and Kortum (2002), $\varepsilon=-\theta$, is independent of the intensive margin elasticity, $1-\sigma$. This particular feature of Eaton and Kortum (2002) model can be explained as follows. On the one hand, changes in relative imports at the intensive margin are given by $(1-\sigma) d \ln c_{i j}$, just like in the Armington model. On the other hand, changes at the extensive margin are given by $(\sigma-1-\theta) d \ln c_{i j}$. By adding the effects of these two margins, we obtain $d \ln \lambda_{i j}-d \ln \lambda_{j j}=-\theta d \ln c_{i j}$. A similar feature has already been discussed in the context of the Melitz (2003) model by Chaney (2008), Arkolakis et al. (2008), and Feenstra (2009).
} 
gains from trade, not their total size.

A natural question at this point is: Are there many other Ricardian models, beyond Eaton and Kortum (2002), that satisfy R3? The short answer is: "Probably not." The same way that Dixit-Stiglitz preferences are crucial in guaranteeing the existence of a unique trade elasticity in what boils down to a simple endowment economy in Section 2, it is hard to imagine R3 holding in a Ricardian economy in the absence of very specific functional forms on the distribution of unit labor requirements. ${ }^{18}$ That being said, it should be clear that, like in Section 2, functional forms are only crucial for our results to the extent that we are interested in arbitrary shocks. If only small shocks are considered, a simple example in which the import demand system is locally CES - and hence a local version of Proposition 1 holds - is the case of a symmetric free trade equilibrium. In this case, all extensive margin elasticities are equal, and so by Equation (15), for any importer $j$ and any pair of exporters $i \neq j$ and $i^{\prime} \neq j, \varepsilon_{j}^{i i^{\prime}}=\varepsilon<0$ if $i=i^{\prime}$, and zero otherwise.

\subsection{The Melitz (2003) Model}

We now turn to the case of monopolistic competition with free entry and firm heterogeneity à la Melitz (2003). This second example again abstracts from endogenous technological choices, $\underline{t}=\bar{t}=1$ (with $m_{i j}(1)=1$ ), assumes that good-specific unit labor requirements do not vary across destinations, $\alpha_{i j}(\omega) \equiv \alpha_{i}(\omega)$, and ignores heterogeneity in fixed costs, $\phi_{i j}(\omega)=1$ for all $i, j, \omega$. Like in the Ricardian model, we denote by $G\left(\alpha_{1}, \ldots, \alpha_{n}\right)$ the share of goods $\omega \in \Omega$ such that $\alpha_{i}(\omega) \leq \alpha_{i}$ for all $i$, and by $g\left(\alpha_{1}, \ldots, \alpha_{n}\right)$ the associated density function. Finally, we assume that exporting and importing country wages matter for fixed exporting costs through a Cobb-Douglas function, $h_{i j}\left(w_{i}, w_{j}\right)=w_{i}^{\mu} w_{j}^{1-\mu}, \mu \in[0,1]{ }^{19}$

Aggregate trade flows. Under monopolistic competition with Dixit-Stiglitz preferences, firms charge a constant markup, $\sigma /(\sigma-1)$, over marginal costs. The associated profits (net of fixed exporting costs) of a producer of good $\omega$ in country $i$ selling in country $j$ are thus given by $\pi_{i j}(\omega)=\left[\sigma c_{i j} \alpha_{i j}(\omega) /(\sigma-1) P_{j}\right]^{1-\sigma}\left(Y_{j} / \sigma\right)-\xi_{i j} w_{i}^{\mu} w_{j}^{1-\mu}$, where we again use the notation

\footnotetext{
${ }^{18}$ Wilson (1980) provides an early discussion of the relationship between Ricardian and endowment models.

${ }^{19}$ Strictly speaking, the present example is more general than Melitz (2003) in that it allows for asymmetry across acountries, as in Chaney (2008), and for marketing costs to be paid in multiple countries, as in Arkolakis (2010). The original Melitz (2003) model corresponds to the particular case in which $\mu=1$.
} 
$c_{i j} \equiv w_{i} \tau_{i j}$. Denoting $\alpha_{i j}^{*}$ the cutoff determining the entry of firms from country $i$ in country $j$, i.e. $\pi_{i j}(\omega)>0$ if and only if $\alpha_{i j}(\omega)<\alpha_{i j}^{*}$, the set of goods $\Omega_{i j}$ that country $j$ buys from country $i$ can be written as

$$
\Omega_{i j}=\left\{\omega \in \Omega \mid \alpha_{i j}(\omega)<\alpha_{i j}^{*} \equiv \sigma^{\frac{\sigma}{1-\sigma}}(\sigma-1)\left(\frac{P_{j}}{c_{i j}}\right)\left(\frac{\xi_{i j} w_{i}^{\mu} w_{j}^{1-\mu}}{Y_{j}}\right)^{\frac{1}{1-\sigma}}\right\} .
$$

Combining this observation with Dixit-Stiglitz preferences, we get

$$
X_{i j}=\frac{N_{i} \int_{0}^{\alpha_{i j}^{*}}\left[c_{i j} \alpha_{i}\right]^{1-\sigma} g_{i}\left(\alpha_{i}\right) d \alpha_{i}}{\sum_{i^{\prime}=1}^{n} N_{i^{\prime}} \int_{0}^{\alpha_{i^{\prime} j} j}\left[c_{i^{\prime} j} \alpha_{i^{\prime}}\right]^{1-\sigma} g_{i^{\prime}}\left(\alpha_{i^{\prime}}\right) d \alpha_{i^{\prime}}} Y_{j},
$$

where the density $g_{i}\left(\alpha_{i}\right)$ of goods with unit labor requirements $\alpha_{i}$ in $\Omega_{i j}$ is simply given by the marginal density of $g \cdot{ }^{20} \quad$ Noting that $\partial \ln \alpha_{i j}^{*} / \partial \ln \tau_{i j}=\partial \ln \alpha_{j j}^{*} / \partial \ln \tau_{i j}-1$ and $\partial \ln \alpha_{i j}^{*} / \partial \ln \tau_{i^{\prime} j}=\partial \ln \alpha_{j j}^{*} / \partial \ln \tau_{i^{\prime} j}$ if $i^{\prime} \neq i$, the import demand system now satisfies

$$
\frac{\partial \ln \left(X_{i j} / X_{j j}\right)}{\partial \ln \tau_{i^{\prime} j}}=\varepsilon_{j}^{i i^{\prime}}=\left\{\begin{array}{ll}
1-\sigma-\gamma_{i j}+\left(\gamma_{i j}-\gamma_{j j}\right)\left(\frac{\partial \ln \alpha_{j j}^{*}}{\partial \ln \tau_{i j}}\right) & \text { for } i^{\prime}=i \\
\left(\gamma_{i j}-\gamma_{j j}\right)\left(\frac{\partial \ln \alpha_{j j}^{*}}{\partial \ln \tau_{i^{\prime} j}}\right) & \text { for } i^{\prime} \neq i
\end{array},\right.
$$

where $\gamma_{i j} \equiv d \ln \int_{0}^{\alpha_{i j}^{*}} \alpha^{1-\sigma} g_{i}(\alpha) d \alpha / d \ln \alpha_{i j}^{*}$ is the counterpart of the extensive margin elasticities under perfect competition.

Welfare predictions. As in the case of perfect competition, we now demonstrate how the logic of Section 2 carries over from the Armington model to this richer environment provided that R1-R3 hold. Under free entry, labor market clearing and the representative agent's budget constraint still imply $d \ln Y_{j}=d \ln w_{j}=0$, where the second equality again derives from the choice of labor in country $j$ as our numeraire. A key difference between this example and the previous one is that changes in the consumer price index no longer satisfy $d \ln P_{j}=\sum_{i=1}^{n} \lambda_{i j} d \ln c_{i j}$, reflecting the fact that, under monopolistic competition, consumers are not necessarily indifferent between the "cutoff" goods produced by different countries. Formally, small changes in real

\footnotetext{
${ }^{20}$ Formally, we now have $g_{i}\left(\alpha_{i}\right)=\int_{\alpha_{1} \geq 0} \cdots \int_{\alpha_{i-1} \geq 0} \int_{\alpha_{i+1} \geq 0} \cdots \int_{\alpha_{n} \geq 0} g(\boldsymbol{\alpha}) d \boldsymbol{\alpha}_{-i}$.
} 
income are now given by

$$
d \ln W_{j}=-d \ln P_{j}=-\sum_{i=1}^{n} \lambda_{i j}\left(d \ln c_{i j}+\frac{d \ln N_{i}+\gamma_{i j} d \ln \alpha_{i j}^{*}}{1-\sigma}\right)
$$

Using the definition of the cutoff $\alpha_{i j}^{*}$ this Equation can be rearranged as

$d \ln W_{j}=-\sum_{i=1}^{n}\left(\frac{\lambda_{i j}}{1-\sigma-\gamma_{j}}\right) \cdot\left[\left(1-\sigma-\gamma_{i j}\right) d \ln c_{i j}+\frac{\gamma_{i j}}{1-\sigma}\left(d \ln \xi_{i j}+\mu d \ln w_{i}\right)+d \ln N_{i}\right]$,

where $\gamma_{j} \equiv \sum_{i} \lambda_{i j} \gamma_{i j}$. Similarly, changes in trade flows are now given by

$d \ln \lambda_{i j}-d \ln \lambda_{j j}=\left(1-\sigma-\gamma_{i j}\right) d \ln c_{i j}+\frac{\gamma_{i j}}{1-\sigma}\left(d \ln \xi_{i j}+\mu d \ln w_{i}\right)+\left(\gamma_{i j}-\gamma_{j j}\right) d \ln \alpha_{j j}^{*}+d \ln N_{i}-d \ln N_{j}$

where we have used the fact that $d \ln \alpha_{i j}^{*}=d \ln \alpha_{j j}^{*}-d \ln c_{i j}+\left(d \ln \xi_{i j}+\mu d \ln w_{i}\right) /(1-\sigma)$. Combining the two previous expressions reveals that

$$
d \ln W_{j}=-\sum_{i=1}^{n}\left(\frac{\lambda_{i j}}{1-\sigma-\gamma_{j}}\right) \cdot\left[d \ln \lambda_{i j}-d \ln \lambda_{j j}-\left(\gamma_{i j}-\gamma_{j j}\right) d \ln \alpha_{j j}^{*}+d \ln N_{j}\right]
$$

Since R3 implies $\gamma_{i j}=\gamma_{j j}$ and $1-\sigma-\gamma_{j}=\varepsilon$ for all $i, j$, we obtain $d \ln W_{j}=\left(d \ln \lambda_{j j}-d \ln N_{j}\right) / \varepsilon$, in the exact same way as in the previous example. To conclude, we simply note that free entry implies $\Pi_{j}=N_{j} F_{j}$. Since $\Pi_{j}$ is proportional to $Y_{j}$ by $\mathrm{R} 1$ and $\mathrm{R} 2$, we therefore have $d \ln N_{j}=d \ln Y_{j}=0$. Combining the two previous observations and integrating, we again get $\widehat{W}_{j}=\widehat{\lambda}_{j j}^{1 / \varepsilon}$.

What is the role of our macro-level restrictions? Compared to the Ricardian model, R1 and R2 now play a substantial role. Together, they imply that aggregate profits are a constant share of total expenditure, which guarantees that the measure $N_{j}$ of goods that can be produced in country $j$ is not affected by foreign shocks. ${ }^{21}$ By contrast, R3 plays the exact same role as in the Ricardian model, namely that small changes in each component of the consumer price index can be inferred one-by-one from changes in relative imports, then aggregated into small changes in the share of domestic expenditure, and finally integrated into large changes to get Proposition 1.

\footnotetext{
${ }^{21}$ Under restricted entry, R1 and R2 would play an analogous role by guaranteeing that aggregate profits are not affected by foreign shocks; see proof of Proposition 1 in Appendix A.2.
} 
Before discussing when R1-R3 hold, we wish to stress that the fact that $N_{j}$ is not affected by foreign shocks - which is crucial for our welfare results - by no means implies that the measure of goods consumed in country $j$ is fixed. In particular, changes in both the foreign cutoffs, $\alpha_{i j}^{*}$, and the measure of goods that can be produced abroad, $N_{i}$, will affect the number and price of foreign goods consumed in country $j$. Hence our example allows for "gains from new varieties" in the sense in which these gains are commonly measured; see e.g. Feenstra (1994) and Broda and Weinstein (2006). Similarly, the fact that $N_{j}$ is constant by no means implies that foreign shocks have no effect on intra-industry reallocations in country $j$. For instance, if a given episode of trade liberalization increases the domestic cut-off, $\alpha_{j j}^{*}$, the number of active firms in country $j$ will decrease with labor being reallocated from the least to the most efficient firms as documented in many micro-level studies; see e.g. Trefler (2004).

When are our macro-level restrictions satisfied? Under monopolistic competition, R1 and R2 are no longer trivial restrictions, as already mentioned in Section 3.2. Similarly, like in a Ricardian model, R3 is unlikely to hold under monopolistic competition without strong functional form restrictions.

By far the most common restriction on technology imposed in the literature on monopolistic competition with firm heterogeneity emanating from Melitz (2003) is that firm-productivity levels are randomly drawn from a Pareto distribution. ${ }^{22}$ Using our notations, the Pareto case corresponds to a situation in which the marginal densities of $g$ are such that

$$
g_{i}\left(\alpha_{i}\right)=\frac{\theta \alpha_{i}^{\theta-1}}{{\overline{\alpha_{i}}}^{\theta}}, \text { for all } 0 \leq \alpha_{i} \leq \bar{\alpha}_{i}
$$

If Equation (22) holds, our three macro-level restrictions are satisfied. Using labor market clearing, it is a simple matter of algebra to check that R1 and R2 are satisfied. Using Equation

\footnotetext{
${ }^{22}$ Although not part of the original theoretical framework developed by Melitz (2003), this distributional assumption is invoked, for example, in Antras and Helpman (2004), Helpman, Melitz and Yeaple (2004), Ghironi and Melitz (2005), Bernard, Redding and Schott (2007), Arkolakis (2010), Chaney (2008), Feenstra and Kee (2008), Hanson and Xiang (2008), Melitz and Ottaviano (2008), Feenstra (2009), Helpman and Itskhoki (2010), Di Giovanni and Levchenko (2010), Arkolakis and Muendler (2010), Helpman, Itskhoki and Redding (2010), Hsieh and Ossa (2010), and, as previously mentioned, in Eaton, Kortum and Kramarz (2010). While analytical convenience has clearly contributed to the popularity of Pareto distributions among trade economists, there exist both empirical and theoretical reasons that favor this distributional assumption. As documented by Axtell (2001) and Eaton, Kortum, and Kramarz (2010), among others, Pareto distributions provide a reasonable approximation for the right tail of the observed distribution of firm sizes. From a theoretical standpoint, these distributions are also consistent with simple stochastic processes for firm-level growth, entry, and exit; see e.g. Simon (1955), Gabaix (1999) and Luttmer (2007).
} 
(22) and the definition of $\gamma_{i j}$, it is also easy to check that $\gamma_{i j}=\gamma_{j j}=1-\sigma+\theta$ and hence R3 is satisfied with $\varepsilon=-\theta$. Moreover, combining Equation (20), Equation (22), and the definition of $\alpha_{i j}^{*}$, we obtain

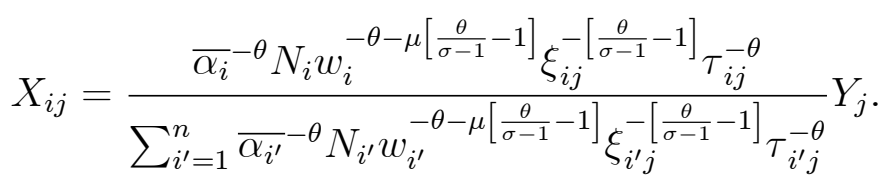

Interestingly, Equation (23) shows that whereas R3 always holds in the Pareto case, our stronger macro-level restriction R3' is only satisfied if $\mu=0$, i.e. if fixed exporting costs are paid in the importing country. ${ }^{23}$

Like in Section 4.1, the introduction of new margins of adjustment changes the structural interpretation of the trade elasticity, $\varepsilon$, from a preference parameter, $1-\sigma$, to a technological parameter, $-\theta$. Yet, because our three macro-level restrictions R1-R3 are satisfied, the total gains from trade can still be computed using only two statistics, $\lambda_{j j}$ and $\varepsilon$, as stated in Corollary 1. By contrast, because R3' no longer holds under monopolistic competition if $\mu>0$, one would need additional information, namely on $\mu$ and $\sigma$, to predict ex ante the welfare consequences of an arbitrary change in variable trade costs. In such circumstances, the empirical approach developed by Helpman, Melitz and Rubinstein (2008) could prove particularly useful since it allows researchers to estimate separately the trade elasticity, $\varepsilon$, and the intensive margin elasticity, $1-\sigma$. We come back to estimation issues in Section 6 .

We wish to be clear that R3 again requires strong functional form restrictions for intensive and extensive margin elasticities "to behave in the same way." Depending on the market structure, perfect or monopolistic competition, we see that these functional form restrictions are different, Fréchet or Pareto, reflecting the different nature of selection into exports in these environment; see Equations (13) and (19). ${ }^{24}$ In our view, the main advantage of R3 over particular functional form restrictions, such as Equations (17) and (22), is to provide a unifying

\footnotetext{
${ }^{23}$ This is the situation considered, for instance, in Eaton, Kortum and Kramarz (2010). Compared to the Melitz (2003) model presented in this section, Eaton, Kortum and Kramarz (2010) also includes heterogeneity in fixed costs and endogenous technology adoption, as formalized in Section 3. Using our notations, however, bilateral trade flows in Eaton, Kortum and Kramarz (2010) also satisfy Equation (23) with $\mu=0$, and therefore, R3'; see Equation (20), page 16 in Eaton, Kortum and Kramarz (2010).

${ }^{24}$ Like under perfect competition, it should be clear that strong functional forms are only crucial to the extent that we are interested in arbitrary shocks. For instance, if only small foreign shocks are considered and the initial trade equilibrium is fully symmetric, then the import demand system always is locally CES. If, in addition, fixed exporting costs are paid in domestic labor $(\mu=0)$, this immediately implies that a local version of Proposition 1 holds as well (since R1 and R2 necessarily hold in this case).
} 
perspective on the economic mechanisms responsible for the equivalence across quantitative trade models, independently of their market structure.

\section{$5 \quad$ Extensions}

In this section we briefly discuss how our results would be affected by departures from the primitive assumptions imposed in Section 3.1. Motivated by the existing trade literature, we consider extensions of quantitative trade models with multiple sectors, as in Chor (2010), Donaldson (2008), Costinot, Donaldson and Komunjer (2010), and Caliendo and Parro (2010) and tradable intermediate goods, as in Eaton and Kortum (2002), Alvarez and Lucas (2007), Waugh (2010), Atkeson and Burstein (2010) and Di Giovanni and Levchenko (2009). We conclude by mentioning other extensions such as multiple factors of production and variable mark-ups. A detailed analysis of the extensions to multiple sectors and tradable intermediate goods can be found in the online appendix. Here we limit ourselves to a summary of our main findings.

\subsection{Multiple Sectors}

It is standard to interpret models with Dixit-Stiglitz preferences, such as the one presented in Section 3.1, as "one-sector" models with a continuum of "varieties"; see e.g. Helpman and Krugman (1985). Under this interpretation, our model can be extended to multiple sectors, $s=1, \ldots, S$, by assuming that the representative agent has a two-tier utility function, with the upper-tier being Cobb-Douglas, with consumption shares $0 \leq \eta^{s} \leq 1$, and the lower-tier being Dixit-Stiglitz with elasticity of substitution $\sigma^{s}>1$. In this case, the consumer price index in country $j$ becomes $P_{j}=\prod_{s=1}^{S}\left(P_{j}^{s}\right)^{\eta^{s}}$, where $P_{j}^{s}$ is the Dixit-Stiglitz price index associated with varieties from sector $s$, as described in Equation (7).

Assuming that technology and market structure remain as described in Section 3.1 and that our three macro-level restrictions now hold sector-by-sector, ${ }^{25}$ the change in real income

\footnotetext{
${ }^{25}$ For R2 and R3, we simply mean that our macro-level restrictions now apply to $\Pi_{j}^{s}, R_{j}^{s}$, and $\left\{X_{i j}^{s}\right\}$. In the case of R1, we do not mean that trade is balanced sector-by-sector, which would not be true in models considered in the literature. Rather we mean that $w_{j} L_{j}^{s}+\Pi_{j}^{s}-w_{j} N_{j}^{s} F_{j}^{s}=R_{j}^{s} \equiv \sum_{i=1}^{n} X_{j i}^{s}$ for all $s=1, \ldots, S$. This restriction is the sector-by-sector version of $\mathrm{R} 1$ when we write this restriction for the one-sector environment as $w_{j} L_{j}+\Pi_{j}-w_{j} N_{j} F_{j}=R_{j}$, which is of course equivalent to trade balance given the representative agent's budget constraint in country $j$.
} 
associated with an arbitrary foreign shock generalizes to:

$$
\begin{array}{ll}
\widehat{W}_{j}=\prod_{s=1}^{S}\left(\widehat{\lambda}_{j j}^{s}\right)^{\eta_{j}^{s} / \varepsilon^{s}} & , \text { under perfect competition, } \\
\widehat{W}_{j}=\prod_{s=1}^{S}\left(\hat{\lambda}_{j j}^{s} / \widehat{L}_{j}^{s}\right)^{\eta_{j}^{s} / \varepsilon^{s}} & , \text { under monopolistic competition with free entry, }
\end{array}
$$

where $\lambda_{j j}^{s} \geq 0$ represents the share of expenditure devoted to domestic goods in sector $s$; and $\varepsilon^{s}<0$ and $L^{s} \geq 0$ are the trade elasticity and total employment in that sector, respectively. The new formula under perfect competition is a straightforward generalization of Proposition 1 , and requires no explanation. To understand the appearance of $\widehat{L}_{j}^{s}$ in our welfare formula under monopolistic competition with free entry, it is useful to go back to the example of Section 4.2. In that case, R3 implied that the welfare effect of a foreign shock was given by $\widehat{W}_{j}=\left(\widehat{\lambda}_{j j} / \widehat{N}_{j}\right)^{1 / \varepsilon}$. But since the supply of labor was inelastic, Restrictions R1 and R2 lead to $\widehat{N}_{j}=\widehat{L}_{j}=1$, and so, $\widehat{W}_{j}=\widehat{\lambda}_{j j}^{1 / \varepsilon}$. By contrast, in a multi-sector environment, the supply of labor in each sector is no longer inelastic: foreign shocks may lead to changes in sector-level employment with consequences for the measure of goods that can be produced, i.e. $\widehat{N}_{j}^{s}=\widehat{L}_{j}^{s} \neq 1$. This is the key idea behind our generalized formula. ${ }^{26}$

Compared to the results presented in Section 3, we see that the welfare consequences of foreign shocks, in general, and the gains from trade, in particular, may no longer be the same under perfect and monopolistic competition with free entry. As our previous discussion emphasized, the equivalence between these two classes of quantitative trade models relied on the fact that there was no change in the measure of goods $N_{j}$ that can be produced in country $j$, which may no longer be true in all sectors. ${ }^{27}$ That being said, it is important to note that there is no particular reason for gains from trade to be higher (or lower) under monopolistic than under perfect competition. Although gains from trade are larger in sectors in which the set of goods that can be produced expands, $\widehat{N}_{j}^{s}>0$, they are lower in those in which it contracts, $\widehat{N}_{j}^{s}<0$, the overall effect depending on whether $\prod_{s=1}^{S}\left(\widehat{L}_{j}^{s}\right)^{\eta_{j}^{s} / \varepsilon^{s}}$ is higher or lower than one.

\footnotetext{
${ }^{26}$ The same logic implies that our welfare formula under monopolistic competition with restricted entry would be exactly the same as under perfect competition.

${ }^{27}$ In a related paper, Balistreri, Hillberry and Rutherford (2009) have developed variations of the Armington and Melitz (2003) models with a non-tradeable sector to illustrate the same idea: if changes in trade costs lead to changes in the measure of goods that can be produced, then models with perfect and monopolistic competition no longer have the same welfare implications.
} 


\subsection{Tradable Intermediate Goods}

In Section 3 all goods were for final consumption. In this extension we allow goods $\omega \in \Omega$ to be used in the production of other goods. Formally, we assume that all goods can be aggregated into a unique intermediate good using the same Dixit-Stigliz aggregator as for final consumption. Thus, $P_{i}$ now represents both the consumer price index in country $i$ and the price of intermediate goods in this country. Accordingly, the cost function for each good $\omega$ is given by

$$
C_{i}(\boldsymbol{w}, \boldsymbol{P}, \boldsymbol{q}, \boldsymbol{t}, \omega)=\sum_{j=1}^{n}\left[c_{i j}\left(w_{i}, P_{i}, t_{j}, \omega\right) q_{j}+f_{i j}\left(w_{i}, P_{i}, w_{j}, P_{j}, t_{j}, \omega\right) \mathbb{I}\left(q_{j}>0\right)\right]
$$

where $\boldsymbol{P} \equiv\left\{P_{i}\right\}$ is the vector of intermediate good prices. In line with the previous literature we further assume that constant marginal costs and fixed exporting costs can be written as

$$
\begin{aligned}
c_{i j}\left(w_{i}, P_{i}, t_{j}, \omega\right) & \equiv \tau_{i j} \cdot w_{i}^{\beta} \cdot P_{i}^{1-\beta} \cdot \alpha_{i j}(\omega) \cdot t_{j}^{\frac{1}{1-\sigma}}, \\
f_{i j}\left(w_{i}, P_{i}, w_{j}, P_{j}, t_{j}, \omega\right) & \equiv \xi_{i j} \cdot h_{i j}\left(w_{i}^{\beta} P_{i}^{1-\beta}, w_{j}^{\beta} P_{i}^{1-\beta}\right) \cdot \phi_{i j}(\omega) \cdot m_{i j}\left(t_{j}\right),
\end{aligned}
$$

with $\beta \in[0,1]$ governing the share of intermediate goods in variable and fixed production costs. Similarly, we assume that fixed entry costs (if any) are given by $w_{i}^{\kappa} P_{i}^{1-\kappa} F_{i}$, with $\kappa \in[0,1]$ governing the share of intermediate goods in entry costs. In this environment the change in real income associated with an arbitrary foreign shock in country $j$ generalizes to:

$$
\begin{array}{ll}
\widehat{W}_{j}=\widehat{\lambda}_{j j}^{1 / \varepsilon \beta} & , \text { under perfect competition, } \\
\widehat{W}_{j}=\widehat{\lambda}_{j j}^{1 /\left[\varepsilon \beta-(1-\beta)\left(\frac{\varepsilon}{\sigma-1}+1\right)+(1-\kappa)\right]} & , \text { under monopolistic competition with free entry, }
\end{array}
$$

where $\varepsilon$ now refers to the trade elasticity of the import demand system defined as a mapping from $(\boldsymbol{w}, \boldsymbol{P}, \boldsymbol{N}, \boldsymbol{\tau})$ into $\boldsymbol{X} .{ }^{28}$ Under perfect competition, the fact that tradable intermediate goods are used to produce tradable intermediate goods creates an input-output loop that amplifies the gains from trade. The higher the share of intermediate goods in production (i.e., the lower is $\beta$ ), the higher this amplification effect. Under monopolistic competition with free entry there are two additional amplification mechanisms associated with the decrease in fixed exporting

\footnotetext{
${ }^{28}$ This generalization of the definition of the import demand system reflects the fact that there are now two inputs in production, labor and the aggregate intermediate goods, with prices given by $\boldsymbol{w}$ and $\boldsymbol{P}$, respectively.
} 
and entry costs, both of which increase the number of consumed varieties in country $j .^{29}$ The second of these amplification mechanisms is reminiscent of the effect of trade on growth in the "lab equipment" model; see Rivera-Batiz and Romer (1991).

Just as in the case of multiple sectors, we see that our welfare formula is no longer the same under perfect and monopolistic competition. There is, however, an important difference between our two extensions. In the case of multiple sectors, the effect of trade on entry under monopolistic competition could either lead to higher or lower gains from trade. This is no longer the case here: the gains from trade are unambiguously larger under monopolistic than perfect competition.

\subsection{Other Extensions}

We end this section by mentioning two additional extensions: multiple factors of production and variable mark-ups. A simple way to introduce multiple factors of production into our general framework is to assume that: $(i)$ there are multiple sectors, as in Section $5.1 ;(i i)$ all goods from the same sector have the same factor intensity; but (iii) factor intensity differs across sectors; see e.g. Bernard, Redding and Schott (2007) and Burstein and Vogel (2010). Under perfect competition, the reasoning presented in the previous sections remains valid up to a point: the formula in Proposition 1 now needs to be augmented to reflect changes in relative factor prices domestically. This is because sector-level trade flows cannot tell us what is fundamentally an economy-wide impact of trade on factor prices. Under monopolistic competition, this issue is complicated by the implications of trade for the measure of goods that can be produced in different sectors, as discussed earlier. ${ }^{30}$

Throughout this paper, we have focused on trade models with constant mark-ups, either because of perfect competition or monopolistic competition with Dixit-Stiglitz preferences. Allowing for quasi-linear preferences or translog expenditure functions, as in Melitz and Ottaviano

\footnotetext{
${ }^{29}$ Under monopolistic competition with free entry, Equation (23) shows that a decline in the fixed cost of serving the domestic market $\left(\xi_{j j}\right)$ increases the domestic trade share $\left(\lambda_{j j}\right)$ with an elasticity $-\left(\frac{\varepsilon}{\sigma-1}+1\right)$ while a decline in the entry cost $\left(F_{j}\right)$ increases $\lambda_{j j}$ with a unitary elasticity. The term $-(1-\beta)\left(\frac{\varepsilon}{\sigma-1}+1\right)+(1-\kappa)$ inside the bracket in the welfare formula above follows from the fact that a decline in $P_{j}$ decreases the fixed trade cost and the entry cost with elasticities $1-\beta$ and $1-\kappa$, respectively.

${ }^{30}$ These complications notwithstanding, explicit welfare formulas can still be obtained in the case of CobbDouglas production functions, as demonstrated formally in Arkolakis, Costinot and Rodríguez-Clare (2009).
} 
(2008) and Feenstra and Weinstein (2009), or Bertrand competition, as in Bernard, Eaton, Jensen and Kortum (2003), would introduce variations in mark-ups, and hence, a new source of gains from trade. While the introduction of these pro-competitive effects, which falls outside the scope of the present paper, would undoubtedly affect the composition of the gains from trade, our formal analysis is a careful reminder that it may not affect their total size. In fact, it is easy to check that in Bernard et al. (2003), our simple welfare formula remains unchanged in spite of variable mark-ups at the firm-level. The same is true under monopolistic competition with translog expenditure functions if firm productivity levels are drawn from a Pareto distribution, as shown in Arkolakis, Costinot and Rodriguez-Clare (2010).

\section{Estimating the Trade Elasticity}

In the previous sections, we have demonstrated how the welfare implications of quantitative trade models, as defined in Section 3, crucially depend on two sufficient statistics: $(i)$ the share of expenditure on domestic goods, $\lambda_{j j}$; and $(i i)$ the trade elasticity, $\varepsilon$. While the first of these two statistics can be readily computed from official statistics, the second cannot. The trade elasticity needs to be estimated and this estimation may, in principle, depend on the details of the model. Put simply, whereas all quantitative trade models imply that the gains from trade are equal to $1-\lambda^{-1 / \varepsilon}$, our analysis so far leaves open the possibility that the estimate of $\varepsilon$ itself is model specific.

In this section we will argue that, in spite of the different possible structural interpretations of the trade elasticity in the class of models considered in this paper, this is, to a large extent, not the case. Independently of their micro-level predictions, the "gravity equation" offers a common way to estimate the trade elasticity across different quantitative trade models, and therefore, together with Corollary 1, a common estimator of the gains from trade.

There is more than one formal definition of the "gravity equation" in the trade literature. Here we adopt a fairly broad definition, consistent with Anderson (2010), and say that a trade model satisfies a gravity equation if it predicts that in any cross-section, bilateral imports can be decomposed into:

$$
\ln X_{i j}=A_{i}+B_{j}+\gamma \ln \tau_{i j}+\nu_{i j}
$$


where $A_{i}$ is an exporter-specific term; $B_{j}$ is an importer-specific term; $\gamma$ is the partial elasticity of bilateral imports with respect to variable trade costs; and $\nu_{i j}$ captures country-pair specific parameters that are distinct from variable trade costs (if any). Under standard orthogonality conditions, Equation (24) offers a simple way to estimate $\gamma$ using observed measures of bilateral imports and variable trade costs; see e.g. Anderson and Van Wincoop (2004).

Given the previous definition, it is immediate that a quantitative trade model satisfying R3' also satisfies gravity with the partial elasticity of bilateral imports $\gamma$ being equal to the trade elasticity $\varepsilon .^{31}$ Thus, within this class of models, provided that the same orthogonality condition is invoked, gravity offers a common estimator of the trade elasticity, and in turn, of the overall gains from trade. What if a quantitative trade model does not satisfy R3'? In this situation, bilateral trade flows may not, in principle, satisfy gravity as defined in Equation (24). For existing quantitative trade models, however, bilateral imports can always - to the best of our knowledge - be decomposed into $X_{i j}=\frac{\chi_{i j} \cdot N_{i} \cdot w_{i}^{\varepsilon^{\prime}} \cdot \tau_{i j}^{\varepsilon} \cdot Y_{j}}{\sum_{i^{\prime}=1}^{n} \chi_{i^{\prime} j} \cdot N_{i^{\prime}} \cdot w_{i^{\prime}}^{\varepsilon^{\prime}} \cdot \tau_{i^{\prime} j}^{\varepsilon}}$. Although R3' is not satisfied if $\varepsilon^{\prime} \neq \varepsilon$, it is still the case that $\varepsilon$ can be recovered from a simple gravity equation. ${ }^{32}$ Thus, within that extended class of models, there remains a common estimator of the gains from trade.

As hinted above, a key issue for a common estimator of the gains from trade to exist is that the same orthogonality condition can be invoked across different models. In our view, this issue is primarily an econometric one, which we have little to contribute to. To be more specific, suppose that variable trade costs are being measured using tariff data; see e.g. Baier and Bergstrand (2001). ${ }^{33}$ In order to obtain unbiased estimates of $\varepsilon$ using a gravity equation, one needs tariffs to be uncorrelated with the error term associated with Equation (24). Although it is true that this error term may have a different structural interpretation in different modelsand in particular, that it may reflect fixed trade costs under monopolistic competition- the central question remains an econometric one, namely: is the observed component of trade costs uncorrelated with its unobserved component? If so, there will be omitted variable bias, whatever the economic nature of the unobserved component may be.

\footnotetext{
${ }^{31}$ Formally, if a trade model satisfies R3' then it satisfies Equation (24) with $\alpha_{i}=\ln N_{i}+\varepsilon \ln w_{i} ; \beta_{j}=$ $\ln Y_{j}-\ln \left[\sum_{i^{\prime}=1}^{n} N_{i^{\prime}} \cdot\left(w_{i^{\prime}} \tau_{i^{\prime} j}\right)^{\varepsilon}\right] ; \gamma=\varepsilon ;$ and $\nu_{i j}=\ln \chi_{i j}$.

${ }^{32}$ An example of a quantitative trade model with $\varepsilon^{\prime} \neq \varepsilon$ is the Melitz (2003) model presented in Section 4.2 if the share of domestic labor in fixed exporting costs $\mu$ is different from zero.

${ }^{33}$ To the extent that they act as cost-shifters, tariffs can be used, like any other variable trade costs, to obtain estimates of the trade elasticity using a gravity equation. By contrast, our main welfare formula would need to be modified to cover the case of tariffs. In particular, the results derived in Section 3 ignore changes in tariff revenues, which may affect real income both directly and indirectly (through the entry and exit of firms).
} 
Although the gravity equation offers a common estimator of the trade elasticity, we wish to emphasize that it does not offer, in general, the unique estimator of that elasticity. For example, in the Melitz (2003) model presented in Section 4.2, the trade elasticity is equal to the (negative of the) shape parameter of the Pareto distribution of firm-level productivity. Since this Pareto parameter also affects the distribution of firm sales, one can then use micro-level data to estimate $\varepsilon$; see e.g. Di Giovanni and Levchenko (2009). Given the distance between the assumptions needed to estimate parameters from micro data and the key features of aggregate models, however, such an approach is not without its problems; see Heckman and Hansen (1996) for an overview. For the central question in this paper, "how large are the gains from trade?", our view is that estimating the trade elasticity using a gravity equation is a particularly attractive procedure since, by its very nature, it captures by how much aggregate trade flows, and therefore consumption, reacts to changes in trade costs.

\section{Concluding Remarks}

What conclusions should one draw from our theoretical analysis? In our view, two broad messages emerge from our equivalence results.

The first message is a cautionary one. Although it may be tempting to think that new and richer quantitative trade models necessarily entail larger gains from trade, our analysis demonstrates that this is not the case. Within the class of trade models considered in this paper, the number of sources of gains from trade varies, but conditional on observed trade data, the total size of the gains from trade does not. Of course, our equivalence results do not aim to suggest that micro-level data cannot be useful for thinking about the welfare implications of international trade. Rather, our point is that for micro-level data to affect estimates of the gains from trade, these data will have to be used in combination with trade models that fall outside the scope of the present paper, hence our "So far, not much" in the Introduction.

The second message is more positive. The flip side of our strong equivalence results is that within a particular but important class of trade models, there exist two sufficient statistics for welfare analysis: $(i)$ the share of expenditure on domestic goods; and $(i i)$ the trade elasticity. Although quantitative trade models are now able to explain a wider set of micro-level facts, they can still be used for counterfactual analysis using a very limited amount of macro data, 
thereby preserving one of the most attractive features of the simple Armington model. 


\section{References}

Alvarez, Fernando and Robert E. Lucas. 2007. "General Equilibrium Analysis of the Eaton-Kortum Model of International Trade." Journal of Monetary Economics 54(6):1726-1768.

Anderson, James E. 1979. "A Theoretical Foundation for the Gravity Equation." The American Economic Review 69(1):106-116.

Anderson, James E. 2010. "The Gravity Model." forth. Annual Review of Economics .

Anderson, James E. and Eric Van Wincoop. 2003. "Gravity with Gravitas: A Solution to the Border Puzzle." The American Economic Review 93(1):170-192.

Anderson, James E. and Eric Van Wincoop. 2004. "Trade Costs." Journal of Economic Literature 42(3):691-751.

Antras, Pol and Elhanan Helpman. 2004. "Global Sourcing." Journal of Political Economy 112(3):552580.

Arkolakis, Costas. 2010. "Market Penetration Costs and the New Consumers Margin in International Trade." forthcoming, Journal of Political Economy .

Arkolakis, Costas, Arnaud Costinot and Andres Rodríguez-Clare. 2009. "New Trade Models, Same Old Gains?" NBER Working Paper 15628.

Arkolakis, Costas, Arnaud Costinot and Andres Rodriguez-Clare. 2010. "Gains From Trade under Monopolistic Competition: A Simple Example with Translog Expenditure Functions and Pareto Distributions of Firm-Level Productivity.". Manuscript, MIT, Penn State, and Yale University.

Arkolakis, Costas and Marc-Andreas Muendler. 2010. "The Extensive Margin of Exporting Products: A Firm-Level Analysis." NBER Working Paper 16641.

Arkolakis, Costas, Svetlana Demidova, Peter J Klenow and Andres Rodríguez-Clare. 2008. "Endogenous Variety and the Gains from Trade." American Economic Review, Papers and Proceedings 98(4):444-450.

Atkeson, Andrew and Ariel Burstein. 2010. "Innovation, Firm Dynamics, and International Trade." Journal of Political Economy 118(3):433-489.

Axtell, Rob L. 2001. "Zipf Distribution of U.S. Firm Sizes.” Science 293(5536):1818-1820. 
Baier, Scott L. and Jeffrey H. Bergstrand. 2001. "The Growth of World Trade: Tariffs, Transport Costs, and Income Similarity." Journal of International Economics 53(1):1-17.

Balistreri, Edward J., Russell H. Hillberry and Thomas F. Rutherford. 2009. "Trade and Welfare: Does Industrial Organization Matter.”. Manuscript, University of Melbourne.

Bernard, Andew B., Jonathan Eaton, J. Bradford Jensen and Samuel Kortum. 2003. "Plants and Productivity in International Trade." The American Economic Review 93(4):1268-1290.

Bernard, Andrew B., Stephen J. Redding and Peter Schott. 2007. "Comparative Advantage and Heterogeneous Firms." Review of Economic Studies 74(1):31-66.

Bernard, Andrew B., Stephen J. Redding and Peter Schott. 2009. "Multi-Product Firms and Trade Liberalization." NBER Working Paper 12782.

Broda, Cristian and David Weinstein. 2006. "Globalization and the Gains from Variety." Quarterly Journal of Economics 121(2):541-585.

Burstein, Ariel and Jonathan Vogel. 2010. "Globalization, Technology, and the Skill Premium.". Manuscript, Columbia University and UCLA.

Caliendo, Lorenzo and Fernando Parro. 2010. "Estimates of the Trade and Welfare Effects of NAFTA.". Manuscript, University of Chicago.

Chaney, Thomas. 2008. "Distorted Gravity: The Intensive and Extensive Margins of International Trade." The American Economic Review 98(4):1707-1721.

Chetty, Raj. 2009. "Sufficient Statistics for Welfare Analysis: A Bridge Between Structural and Reduced-Form Methods." Annual Review of Economics 1:451-488.

Chor, Davin. 2010. "Unpacking Sources of Comparative Advantage: A Quantitative Approach." forth. Journal of International Economics .

Costinot, Arnaud, Dave Donaldson and Ivana Komunjer. 2010. "What Goods Do Countries Trade? A Quantitative Exploration of Ricardo's Ideas.”. Manuscript, MIT.

Dekle, Robert, Jonathan Eaton and Samuel Kortum. 2008. "Global Rebalancing with Gravity: Measuring the Burden of Adjustment." IMF Staff Papers 55(3):511-540. 
Di Giovanni, Julian and Andrei A. Levchenko. 2009. "Firm Entry, Trade, and Welfare in Zipf's World.". Manuscript, University of Michigan.

Donaldson, Dave. 2008. "Railroads of the Raj: Estimating the Economic Impact of Transportation Infrastructure.". Manuscript, London School of Economics.

Eaton, Jonathan and Samuel Kortum. 2002. "Technology, Geography and Trade." Econometrica 70(5):1741-1779.

Eaton, Jonathan, Samuel Kortum and Francis Kramarz. 2010. "An Anatomy of International Trade: Evidence from French Firms." NBER Working Paper 14610.

Feenstra, Robert. 1994. "New Product Varieties and the Measurement of International Prices." The American Economic Review 84(1):157-177.

Feenstra, Robert. 2009. "Measuring the Gains from Trade under Monopolistic Competition.". Manuscript, University of California, Davis.

Feenstra, Robert and David Weinstein. 2009. "Globalization, Competition, and the U.S. Price Level.". Manuscript, University of California, Davis and Columbia University.

Feenstra, Robert and Hiau Looi Kee. 2008. "Export Variety and Country Productivity: Estimating the Monopolistic Competition Model with Endogenous Productivity." Journal of International Economics 74(2):500-518.

Gabaix, Xavier. 1999. “Zipf's Law for Cities: An Explanation.” Quarterly Journal of Economics 114(3):739-767.

Ghironi, F. and M.J. Melitz. 2005. "International Trade and Macroeconomic Dynamics with Heterogeneous Firms." Quarterly Journal of Economics 120(3):865-915.

Goldberg, P., A. Khandelwal, Nina Pavcnik and P. Topalova. 2009. "Trade Liberalization and New Imported Inputs." American Economic Review, Papers and Proceedings 99(2):494-500.

Hanson, Gordon and Chong Xiang. 2008. "Testing the Melitz Model: An Application to US Motion Picture Exports." NBER Working Paper 14461.

Heckman, James J. and Lars Peter Hansen. 1996. "The Empirical Foundations of Calibration.” Journal of Economic Perspectives 10(1):87-104. 
Helpman, Elhanan, Marc J. Melitz and Stephen R. Yeaple. 2004. "Export Versus FDI with Heterogeneous Firms." The American Economic Review 94(1):300-316.

Helpman, Elhanan, Marc Melitz and Yona Rubinstein. 2008. "Estimating Trade Flows: Trading Partners and Trading Volumes." Quarterly Journal of Economics 2(5):441-487.

Helpman, Elhanan and Oleg Itskhoki. 2010. "Labor Market Rigidities, Trade and Unemployment." Review of Economic Studies 77(3):1100-1137.

Helpman, Elhanan, Oleg Itskhoki and Stephen J. Redding. 2010. "Inequality and Unemployment in a Global Economy." Econometrica 78(4):1239-1283.

Helpman, Elhanan and Paul Krugman. 1985. Market Structure and Foreign Trade: Increasing Returns, Imperfect Competition, and the International Economy. Cambridge, Massachusetts: MIT Press.

Hsieh, Chang-Tai and Ralph Ossa. 2010. "A Global View of Productivity Growth in China and India.". mimeo, University of Chicago.

Klenow, Peter J. and Andres Rodríguez-Clare. 1997. "Quantifying Variety Gains from Trade Liberalization.". Manuscript, University of Chicago.

Krugman, Paul. 1980. "Scale Economies, Product Differentiation, and the Pattern of Trade." The American Economic Review 70(5):950-959.

Luttmer, Erzo G. J. 2007. "Selection, Growth, and the Size Distribution of Firms." Quarterly Journal of Economics 122(3):1103-1144.

Melitz, Marc J. 2003. "The Impact of Trade on Intra-Industry Reallocations and Aggregate Industry Productivity." Econometrica 71(6):1695-1725.

Melitz, Marc J. and Gianmarco I. P. Ottaviano. 2008. "Market Size, Trade, and Productivity." The Review of Economic Studies 75(1):295-316.

Norihiko, Yamano and Nadim Ahmad. 2006. "The OECD Input-Output Database: 2006 Edition." Working Paper 2006/8, OECD .

Rivera-Batiz, Luis A. and Paul M. Romer. 1991. "International Trade with Endogenous Technological Change." European Economic Review 95(971-1001):971-1001.

Simon, Herbert A. 1955. "On a Class of Skew Distribution Functions." Biometrika 42(3/4):425-440. 
Trefler, Daniel. 2004. "The Long and Short of the Canada-US Free Trade Agreement." American Economic Review 94(4):870-895.

Waugh, Mike. 2010. "International Trade and Income Differences." forthcoming, American Economic Review .

Wilson, Charles A. 1980. "On the General Structure of Ricardian Models with a Continuum of Goods: Applications to Growth, Tariff Theory, and Technical Change." Econometrica 48(7):1675-1702. 


\section{A Proof of Proposition 1}

Throughout this Appendix, for any importing country $j$, we denote by $G_{j}\left(\alpha_{1}, \ldots, \alpha_{n}, \phi_{1}, \ldots, \phi_{n}\right)$ the share of goods $\omega \in \Omega$ such that $\alpha_{i j}(\omega) \leq \alpha_{i}$ and $\phi_{i j}(\omega) \leq \phi_{i}$ for all $i$, and by $g_{j}\left(\alpha_{1}, \ldots, \alpha_{n}, \phi_{1}, \ldots, \phi_{n}\right)$ the associated density function. For expositional purposes, we provide separate proofs of Proposition 1 for perfect and monopolistic competition.

\section{A.1 Perfect Competition}

Under perfect competition, it is convenient to use the following additional notations:

$$
\begin{aligned}
& c_{i j} \equiv w_{i} \tau_{i j} \bar{t}^{\frac{1}{1-\sigma}}
\end{aligned}
$$

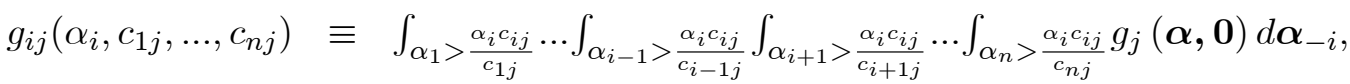

where $\boldsymbol{\alpha} \equiv\left(\alpha_{1}, \ldots, \alpha_{n}\right), \mathbf{0} \equiv(0, \ldots, 0)$, and $\boldsymbol{\alpha}_{-i}$ denotes the vector $\boldsymbol{\alpha}$ with the $i$-th component removed.

In order to establish Proposition 1, we will make use of the following lemma which characterizes the consumer price index, $P_{j}$, and the share of expenditure, $\lambda_{i j}$, on goods from country $i$ in country $j$ under perfect competition.

Lemma 1 Suppose that R3 holds. Then under perfect competition, $P_{j}$ and $\lambda_{i j}$ satisfy

$$
\begin{aligned}
P_{j} & =\left[\sum_{i=1}^{n} \int_{0}^{+\infty}\left(c_{i j} \alpha_{i}\right)^{1-\sigma} \bar{N} g_{i j}\left(\alpha_{i}, c_{1 j}, \ldots, c_{n j}\right) d \alpha_{i}\right]^{\frac{1}{1-\sigma}}, \\
\lambda_{i j} & =\frac{\int_{0}^{+\infty}\left(c_{i j} \alpha_{i}\right)^{1-\sigma} g_{i j}\left(\alpha_{i}, c_{1 j}, \ldots, c_{n j}\right) d \alpha_{i}}{\sum_{i^{\prime}=1}^{n} \int_{0}^{+\infty}\left(c_{i^{\prime} j} \alpha_{i^{\prime}}\right)^{1-\sigma} g_{i^{\prime} j}\left(\alpha_{i^{\prime}}, c_{1 j}, \ldots, c_{n j}\right) d \alpha_{i^{\prime}}}
\end{aligned}
$$

Proof. As pointed out in Section 3.2, there must be complete specialization under R3. Thus we can express the price index and shares of expenditure, respectively, as

$$
\begin{aligned}
P_{j} & =\left[\sum_{i=1}^{n} \int_{\omega \in \Omega_{i j}} p_{j}(\omega)^{1-\sigma} d \omega\right]^{\frac{1}{1-\sigma}}, \\
\lambda_{i j} & =\frac{\int_{\omega \in \Omega_{i j}} p_{j}(\omega)^{1-\sigma} d \omega}{\sum_{i^{\prime}=1}^{n} \int_{\omega \in \Omega_{i^{\prime} j}} p_{j}(\omega)^{1-\sigma} d \omega},
\end{aligned}
$$

where Equation $(A 6)$ directly follows from Equation $(A 5)$ and Shephard's Lemma. Under perfect competition, there are no fixed costs and all firms from country $i$ have free access to all blueprints. Thus profit-maximization implies

$$
p_{j}(\omega)=c_{i j} \alpha_{i j}(\omega), \text { for all } \omega \in \Omega_{i j},
$$

with

$$
\Omega_{i j}=\left\{\omega \in \Omega \mid c_{i j} \alpha_{i j}(\omega)<c_{i^{\prime} j} \alpha_{i^{\prime} j}(\omega) \text { for all } i^{\prime} \neq i\right\}
$$


where $c_{i j}$ is given by Equation $(A 1)$. Note that since the measure of goods for which $c_{i j} \alpha_{i j}(\omega)=$ $c_{i^{\prime} j} \alpha_{i^{\prime} j}(\omega)$ for $i^{\prime} \neq i$ must be zero under complete specialization, the strict inequality in Equation $(A 8)$ is without any loss of generality. Together with the definition of $g_{i j}\left(\alpha_{i}, c_{1 j}, \ldots, c_{n j}\right)$ in Equation $(A 2)$, Equations $(A 5)-(A 8)$ immediately imply Equations $(A 3)$ and $(A 4)$. QED.

We are now ready to establish Proposition 1 under perfect competition.

Proof of Proposition 1 (Perfect competition). We proceed in five steps. Throughout this proof we use labor in country $j$ as our numeraire, $w_{j}=1$.

Step 1: Small changes in real income satisfy

$$
d \ln W_{j}=-d \ln P_{j}
$$

By definition, we know that $d \ln W_{j}=d \ln Y_{j}-d \ln P_{j}$. By labor market clearing and the representative agent's budget constraint, we also know that $d \ln Y_{j}=d \ln w_{j}$. Equation (A9) directly follows from these two observations and the fact that $d \ln w_{j}=0$, by our choice of numeraire.

Step 2: Small changes in the consumer price index satisfy

$$
d \ln P_{j}=\sum_{i=1}^{n} \lambda_{i j} d \ln c_{i j}
$$

By Lemma 1, we know that the consumer price index is given by Equation $(A 3)$. Totally differentiating this expression, we obtain

$$
d \ln P_{j}=\left(\frac{1}{1-\sigma}\right) \cdot \sum_{i=1}^{n} \lambda_{i j}\left[(1-\sigma) d \ln c_{i j}+\sum_{i^{\prime}=1}^{n} \gamma_{i j}^{i^{\prime}} d \ln c_{i^{\prime} j}\right]
$$

where

$$
\gamma_{i j}^{i^{\prime}} \equiv \frac{\partial \ln \left(\int_{0}^{+\infty} \alpha_{i}^{1-\sigma} g_{i j}\left(\alpha_{i}, c_{1 j}, \ldots, c_{n j}\right) d \alpha_{i}\right)}{\partial \ln c_{i^{\prime} j}}
$$

By Equation $(A 2)$, the extensive margin elasticities satisfy $\gamma_{i j}^{i}=-\sum_{i^{\prime} \neq i} \gamma_{i j}^{i^{\prime}}$. Thus we can rewrite Equation $(A 11)$ as

$$
d \ln P_{j}=\sum_{i=1}^{n} \lambda_{i j} d \ln c_{i j}+\left(\frac{1}{1-\sigma}\right) \cdot \sum_{i=1}^{n} \sum_{i^{\prime} \neq i} \lambda_{i j} \gamma_{i j}^{i^{\prime}}\left(d \ln c_{i^{\prime} j}-d \ln c_{i j}\right)
$$

To conclude, note that by Equation (A2), the extensive margin elasticities also satisfy $\lambda_{i j} \gamma_{i j}^{i^{\prime}}=\lambda_{i^{\prime} j} \gamma_{i^{\prime} j}^{i}$, which implies

$$
\sum_{i=1}^{n} \sum_{i^{\prime} \neq i} \lambda_{i j} \gamma_{i j}^{i^{\prime}}\left(d \ln c_{i^{\prime} j}-d \ln c_{i j}\right)=0 .
$$

Combining the two previous expressions, we obtain Equation $(A 10)$.

Step 3: Small changes in the consumer price index satisfy

$$
d \ln P_{j}=\sum_{i=1}^{n} \lambda_{i j}\left(\frac{d \ln \lambda_{i j}-d \ln \lambda_{j j}}{1-\sigma+\gamma_{i j}^{i}-\gamma_{j j}^{i}}-\sum_{i^{\prime} \neq i, j} \frac{\gamma_{i j}^{i^{\prime}}-\gamma_{j j}^{i^{\prime}}}{1-\sigma+\gamma_{i j}^{i}-\gamma_{j j}^{i}} d \ln c_{i^{\prime} j}\right)
$$


By Lemma 1, we know that shares of expenditure are given by Equation $(A 4)$. Totally differentiating this expression, we get

$$
d \ln \lambda_{i j}-d \ln \lambda_{j j}=\left(1-\sigma+\gamma_{i j}^{i}-\gamma_{j j}^{i}\right) d \ln c_{i j}+\sum_{i^{\prime} \neq i, j}\left(\gamma_{i j}^{i^{\prime}}-\gamma_{j j}^{i^{\prime}}\right) d \ln c_{i^{\prime} j}
$$

where we have used $d \ln c_{j j}=0$, by our choice of numeraire. Combining Step 2 and Equation $(A 13)$, we get Equation (A12).

Step 4: Small changes in the consumer price index satisfy

$$
d \ln P_{j}=-\frac{d \ln \lambda_{j j}}{\varepsilon}
$$

Since $d \ln \lambda_{i j}-d \ln \lambda_{j j}=d \ln X_{i j}-d \ln X_{j j}$, Equation (A13) implies, for any $i, i^{\prime} \neq j$,

$$
\frac{\partial \ln \left(X_{i j} / X_{j j}\right)}{\partial \ln \tau_{i^{\prime} j}} \equiv \varepsilon_{j}^{i i^{\prime}}=\left\{\begin{array}{ll}
1-\sigma+\gamma_{i j}^{i}-\gamma_{j j}^{i} & \text { for } \quad i^{\prime}=i \\
\gamma_{i j}^{i^{\prime}}-\gamma_{j j}^{i^{\prime}} & \text { for } \quad i^{\prime} \neq i
\end{array} .\right.
$$

Since R3 holds, the two previous expressions imply $1-\sigma+\gamma_{i j}^{i}-\gamma_{j j}^{i}=\varepsilon$ for all $i \neq j$ and $\gamma_{i j}^{i^{\prime}}=\gamma_{j j}^{i^{\prime}}$ for all $i^{\prime} \neq i, j$. Combining this observation with Step 3, we obtain

$$
d \ln P_{j}=\sum_{i=1}^{n} \lambda_{i j}\left(\frac{d \ln \lambda_{i j}-d \ln \lambda_{j j}}{\varepsilon}\right)
$$

Since $\sum_{i=1}^{n} \lambda_{i j} d \ln \lambda_{i j}=0$, we get Equation $(A 14)$.

Step 5: Changes in real income satisfy

$$
\widehat{W}_{j}=\widehat{\lambda}_{j j}^{1 / \varepsilon}
$$

Combining Steps 1 and 4, we obtain

$$
d \ln W_{j}=\frac{d \ln \lambda_{j j}}{\varepsilon} .
$$

Since $\varepsilon$ is constant across all equilibria, we can integrate Equation ( $A 14)$ between the initial and new equilibrium to get

$$
\widehat{W}_{j}=\frac{W_{j}^{\prime}}{W_{j}}=\left(\frac{\lambda_{j j}^{\prime}}{\lambda_{j j}}\right)^{1 / \varepsilon}=\widehat{\lambda}_{j j}^{1 / \varepsilon}
$$

which concludes the proof of Proposition 1 under perfect competition. QED. 


\section{A.2 Monopolistic Competition}

Under monopolistic competition, it is convenient to use the following additional notations:

$$
\begin{aligned}
\alpha_{i j}^{*} & \equiv \sigma^{\frac{\sigma}{1-\sigma}}(\sigma-1)\left(\frac{P_{j}}{w_{i} \tau_{i j}}\right)\left(\frac{\xi_{i j} h_{i j}\left(w_{i}, w_{j}\right)}{Y_{j}}\right)^{\frac{1}{1-\sigma}}, \\
t_{i j}\left(\alpha, \phi, \alpha_{i j}^{*}\right) & \equiv \arg \max _{t \in T_{i j}}\left[t\left(\frac{\alpha}{\alpha_{i j}^{*}}\right)^{1-\sigma}-m_{i j}(t) \phi\right] \\
c_{i j}\left(\alpha, \phi, \alpha_{i j}^{*}\right) & \equiv w_{i} \tau_{i j}\left(\frac{\sigma}{\sigma-1}\right)\left[t_{i j}\left(\alpha, \phi, \alpha_{i j}^{*}\right)\right]^{\frac{1}{1-\sigma}} \alpha \\
f_{i j}\left(\alpha, \phi, \alpha_{i j}^{*}\right) & \equiv h_{i j}\left(w_{i}, w_{j}\right) \xi_{i j} m_{i j}\left[t_{i j}\left(\alpha, \phi, \alpha_{i j}^{*}\right)\right] \phi \\
\bar{\alpha}_{i j}(\phi) & \equiv \sup \left\{\alpha>0 \mid t_{i j}(\alpha, \phi, 1) \alpha^{1-\sigma}-m_{i j}\left[t_{i j}(\alpha, \phi, 1)\right] \phi>0\right\} \\
g_{i j}(\alpha, \phi) & \equiv \int_{0}^{+\infty} g_{j}\left(\boldsymbol{\alpha}_{-i}, \alpha_{i}=\alpha, \phi_{-i}, \phi_{i}=\phi\right) d \boldsymbol{\alpha}_{-i} d \phi_{-i},
\end{aligned}
$$

where we slightly abuse notations and let $\bar{\alpha}_{i j}(\phi)=+\infty$ if $t_{i j}(\alpha, \phi, 1) \alpha^{1-\sigma}-m_{i j}\left[t_{i j}(\alpha, \phi, 1)\right] \phi>0$ for all $\alpha>0$. Note that $t_{i j}\left(\alpha, \phi, \alpha_{i j}^{*}\right)$ exists by our assumptions on $m_{i j}(t)$ and $T_{i j}$.

In order to establish Proposition 1, we will make use of the following lemma which characterizes the consumer price index, $P_{j}$, the share of expenditure, $\lambda_{i j}$, on goods from country $i$ in country $j$, and aggregate profits gross of entry costs, $\Pi_{j}$, under monopolistic competition.

Lemma 2 Suppose that $R 3$ holds. Then under monopolistic competition, $P_{j}, \lambda_{i j}$, and $\Pi_{j}$ satisfy

$$
\begin{aligned}
P_{j}= & {\left[\sum_{i=1}^{n} N_{i} \int_{0}^{+\infty} \int_{0}^{\bar{\alpha}_{i j}(\phi) \alpha_{i j}^{*}} c_{i j}^{1-\sigma}\left(\alpha, \phi, \alpha_{i j}^{*}\right) g_{i j}(\alpha, \phi) d \alpha d \phi\right]^{\frac{1}{1-\sigma}}, } \\
\lambda_{i j}= & \frac{N_{i} \int_{0}^{+\infty} \int_{0}^{\bar{\alpha}_{i j}(\phi) \alpha_{i j}^{*}} c_{i j}^{1-\sigma}\left(\alpha, \phi, \alpha_{i j}^{*}\right) g_{i j}(\alpha, \phi) d \alpha d \phi}{\sum_{i^{\prime}=1}^{n} N_{i^{\prime}} \int_{0}^{+\infty} \int_{0}^{\bar{\alpha}_{i^{\prime} j}(\phi) \alpha_{i^{\prime} j}^{*}} c_{i^{\prime} j}^{1-\sigma}\left(\alpha, \phi, \alpha_{i^{\prime} j}^{*}\right) g_{i^{\prime} j}(\alpha, \phi) d \alpha d \phi}, \\
\Pi_{j}= & \sum_{i=1}^{n} \frac{N_{j} \int_{0}^{+\infty} \int_{0}^{\bar{\alpha}_{j i}(\phi) \alpha_{j_{i}}^{*}} c_{j i}^{1-\sigma}\left(\alpha, \phi, \alpha_{j i}^{*}\right) g_{j i}(\alpha, \phi) d \alpha d \phi}{\sigma \sum_{i^{\prime}=1}^{n} N_{i^{\prime}} \int_{0}^{+\infty} \int_{0}^{\bar{\alpha}_{i^{\prime} i}(\phi) \alpha_{i^{\prime} i}^{*}} c_{i^{\prime} i}^{1-\sigma}\left(\alpha, \phi, \alpha_{i^{\prime} i}^{*}\right) g_{i^{\prime} i}(\alpha, \phi) d \alpha d \phi} Y_{i} \\
& -\sum_{i=1}^{n} N_{j} \int_{0}^{+\infty} \int_{0}^{\bar{\alpha}_{j i}(\phi) \alpha_{j i}^{*}} f_{i j}\left(\alpha, \phi, \alpha_{j i}^{*}\right) g_{j i}(\alpha, \phi) d \alpha d \phi .
\end{aligned}
$$

Proof. Like under perfect competition, the consumer price index and shares of expenditure can be written, respectively as

$$
\begin{aligned}
P_{j} & =\left[\sum_{i=1}^{n} \int_{\omega \in \Omega_{i j}} p_{j}(\omega)^{1-\sigma} d \omega\right]^{\frac{1}{1-\sigma}}, \\
\lambda_{i j} & =\frac{\int_{\omega \in \Omega_{i j}} p_{j}(\omega)^{1-\sigma} d \omega}{\sum_{i^{\prime}=1}^{n} \int_{\omega \in \Omega_{i^{\prime} j}} p_{j}(\omega)^{1-\sigma} d \omega} .
\end{aligned}
$$


Now consider a firm from country $i$ with a blueprint such that $\alpha_{i j}(\omega)=\alpha$ and $\phi_{i j}(\omega)=\phi$. Under monopolistic competition, this firm chooses its technique $t$ and its price $p$ in country $j$ in order to maximize profits in that market

$$
\pi_{i j}(\alpha, \phi, p, t) \equiv\left[p-w_{i} \tau_{i j} t^{\frac{1}{1-\sigma}} \alpha\right] \frac{p^{-\sigma} Y_{j}}{P_{j}^{1-\sigma}}-h_{i j}\left(w_{i}, w_{j}\right) \xi_{i j} m_{i j}(t) \phi
$$

It is easy to check that the optimal choices $p_{i j}^{*}(\alpha, \phi)$ and $t_{i j}^{*}(\alpha, \phi)$ associated with the first-order conditions of that maximization program satisfy

$$
\begin{aligned}
p_{i j}^{*}(\alpha, \phi) & =c_{i j}\left(\alpha, \phi, \alpha_{i j}^{*}\right), \\
t_{i j}^{*}(\alpha, \phi) & =t_{i j}\left(\alpha, \phi, \alpha_{i j}^{*}\right),
\end{aligned}
$$

where $\alpha_{i j}^{*}, t_{i j}\left(\alpha, \phi, \alpha_{i j}^{*}\right)$, and $c_{i j}\left(\alpha, \phi, \alpha_{i j}^{*}\right)$ are given by Equations $(A 16)-(A 18)$. Now consider the firm's decision to serve country $j$. This firm will serve country $j$ if and only if $\pi_{i j}\left[\alpha, \phi, p_{i j}^{*}(\alpha, \phi), t_{i j}^{*}(\alpha, \phi)\right]>$ 0 , which can be rearranged as

$$
t_{i j}\left(\alpha, \phi, \alpha_{i j}^{*}\right)\left(\frac{\alpha}{\alpha_{i j}^{*}}\right)^{1-\sigma}-m_{i j}\left[t_{i j}\left(\alpha, \phi, \alpha_{i j}^{*}\right)\right] \phi>0
$$

By the envelope theorem, the left-hand side is a strictly decreasing function of $\alpha / \alpha_{i j}^{*}$. Thus, the previous condition is equivalent to $\alpha / \alpha_{i j}^{*}<\bar{\alpha}_{i j}(\phi)$, where $\bar{\alpha}_{i j}(\phi)$ is given by Equation $(A 20)$. In turn the schedule of prices in country $j$ can be written as

$$
p_{j}(\omega)=c_{i j}\left[\alpha_{i j}(\omega), \phi_{i j}(\omega), \alpha_{i j}^{*}\right] \text { for all } \omega \in \Omega_{i j}
$$

with

$$
\Omega_{i j}=\left\{\omega \in \Omega \mid \alpha_{i j}(\omega)<\alpha_{i j}^{*} \bar{\alpha}_{i j}\left[\phi_{i j}(\omega)\right]\right\}
$$

Note that since the measure of firms earning zero profits (net of fixed exporting costs but gross of entry costs) in a particular destination must be zero under R3, as argued in Section 3.2, the strict inequality in Equation $(A 31)$ is without any loss of generality. Together with the definition of $g_{i j}(\alpha, \phi)$ in Equation $(A 21)$, Equations $(A 25),(A 26),(A 30)$, and $(A 31)$ immediately imply Equations $(A 22)$ and $(A 23)$. To conclude the proof of Lemma 2, note that, by definition,

$$
\Pi_{j} \equiv \sum_{i=1}^{n} \int_{\omega \in \Omega_{j i}} \pi_{j i}(\omega) d \omega
$$

Using the previous expression with Equations $(A 27)-(A 31)$, we obtain Equation $(A 24)$ after simple rearrangements. QED.

We are now ready to establish Proposition 1 under monopolistic competition.

Proof of Proposition 1 (Monopolistic Competition). We proceed in five steps. Throughout this proof we use labor in country $j$ as our numeraire, $w_{j}=1$. 
Step 1: Small changes in real income satisfy

$$
d \ln W_{j}=-d \ln P_{j}
$$

By definition, we know that $d \ln W_{j}=d \ln Y_{j}-d \ln P_{j}$. Suppose first that there is free entry in country $j$. In this case, labor market clearing and the representative agent's budget constraint imply $Y_{j}=L_{j}$ since $\Pi_{j}=N_{j} F_{j}$. This immediately implies $d Y_{j}=0$, and in turn, Equation $(A 32)$. Suppose instead that there is restricted entry in country $j$. In this case, labor market clearing and the representative agent's budget constraint imply $Y_{j}=L_{j}+\Pi_{j}$. By R1 and R2, we must also have $\Pi_{j}=\zeta Y_{j}$ with $0<\zeta<1$. Combining the two previous expressions, we get $(1-\zeta) d Y_{j}=0$, which again implies Equation (A32).

Step 2: Small changes in the consumer price index satisfy

$$
\begin{aligned}
d \ln P_{j}= & \sum_{i=1}^{n}\left(\frac{\lambda_{i j}}{1-\sigma-\gamma_{j}}\right) \cdot\left[\left(1-\sigma-\rho_{i j} \gamma_{i j}\right) d \ln w_{i}\right. \\
& \left.+\left(1-\sigma-\gamma_{i j}\right) d \ln \tau_{i j}+d \ln N_{i}-\frac{\gamma_{i j} d \ln \xi_{i j}}{\sigma-1}\right]
\end{aligned}
$$

where $\gamma_{i j}$ is given by Equation (A35) below, $\rho_{i j} \equiv \frac{\partial \ln h_{i j}\left(w_{i}, w_{j}\right) / \partial \ln w_{i}}{\sigma-1}+1$, and $\gamma_{j} \equiv \sum_{i=1}^{n} \lambda_{i j} \gamma_{i j}$.

By Lemma 2, we know that the consumer price index is given by Equation (A22). Totally differentiating this expression, we obtain

$$
(1-\sigma) d \ln P_{j}=\sum_{i=1}^{n} \lambda_{i j}\left[(1-\sigma)\left(d \ln w_{i}+d \ln \tau_{i j}\right)+d \ln N_{i}+\gamma_{i j} d \ln \alpha_{i j}^{*}\right]
$$

where

$$
\begin{aligned}
& \gamma_{i j} \equiv \frac{\int_{\phi_{i j}}^{+\infty} c_{i j}^{1-\sigma}\left[\bar{\alpha}_{i j}(\phi) \alpha_{i j}^{*}, \phi, \alpha_{i j}^{*}\right] \bar{\alpha}_{i j}(\phi) \alpha_{i j}^{*} g_{i j}\left[\bar{\alpha}_{i j}(\phi) \alpha_{i j}^{*}, \phi\right] d \phi}{\int_{0}^{+\infty} \int_{0}^{\bar{\alpha}_{i j}(\phi) \alpha_{i j}^{*}} c_{i j}^{1-\sigma}\left(\alpha, \phi, \alpha_{i j}^{*}\right) g_{i j}(\alpha, \phi) d \alpha d \phi} \\
&+\frac{\int_{0}^{+\infty} \int_{0}^{\bar{\alpha}_{i j}(\phi) \alpha_{i j}^{*}} c_{i j}^{1-\sigma}\left(\alpha, \phi, \alpha_{i j}^{*}\right)\left[\frac{\partial \ln t_{i j}\left(\alpha, \phi, \alpha_{i j}^{*}\right)}{\partial \ln \alpha_{i j}^{*}}\right] g_{i j}(\alpha, \phi) d \alpha d \phi}{\int_{0}^{+\infty} \int_{0}^{\alpha_{i j}(\phi) \alpha_{i j}^{*}} c_{i j}^{1-\sigma}\left(\alpha, \phi, \alpha_{i j}^{*}\right) g_{i j}(\alpha, \phi) d \alpha d \phi}
\end{aligned}
$$

with $\underline{\phi}_{i j}=\inf \left\{\phi>0 \mid \bar{\alpha}_{i j}(\phi)<+\infty\right\}$. By definition of $\alpha_{i j}^{*}$, we also know that

$$
d \ln \alpha_{i j}^{*}=d \ln P_{j}-d \ln \tau_{i j}+\frac{d \ln \xi_{i j}}{1-\sigma}-\rho_{i j} d \ln w_{i}
$$

Combining Equations (A34) and (A36), we get Equation (A33).

Step 3: Small changes in the consumer price index satisfy

$$
d \ln P_{j}=\sum_{i=1}^{n} \lambda_{i j}\left(\frac{d \ln \lambda_{i j}-d \ln \lambda_{j j}}{1-\sigma-\gamma_{j}}\right)+\left(\frac{\gamma_{j j}-\gamma_{j}}{1-\sigma-\gamma_{j}}\right) d \ln \alpha_{j j}^{*}+\frac{d \ln N_{j}}{1-\sigma-\gamma_{j}}
$$


By Lemma 2, we know that shares of expenditure are given by Equation ( $A 23)$. Totally differentiating this expression, we get

$$
d \ln \lambda_{i j}-d \ln \lambda_{j j}=(1-\sigma)\left(d \ln w_{i}+d \ln \tau_{i j}\right)+\gamma_{i j} d \ln \alpha_{i j}^{*}-\gamma_{j j} d \ln \alpha_{j j}^{*}+d \ln N_{i}-d \ln N_{j} .
$$

By definition of $\alpha_{i j}^{*}$, we also know that

$$
d \ln \alpha_{i j}^{*}=d \ln \alpha_{j j}^{*}-\rho_{i j} d \ln w_{i}-d \ln \tau_{i j}+\frac{d \ln \xi_{i j}}{1-\sigma}
$$

The two previous expressions imply

$$
\begin{aligned}
d \ln \lambda_{i j}-d \ln \lambda_{j j}= & \left(1-\sigma-\rho_{i j} \gamma_{i j}\right) d \ln w_{i}+\left(1-\sigma-\gamma_{i j}\right) d \ln \tau_{i j} \\
& +\frac{\gamma_{i j} d \ln \xi_{i j}}{1-\sigma}+\left(\gamma_{i j}-\gamma_{j j}\right) d \ln \alpha_{j j}^{*}+d \ln N_{i}-d \ln N_{j} .
\end{aligned}
$$

Combining Step 2 and Equation (A38), we get Equation (A37).

Step 4: Small changes in the consumer price index satisfy

$$
d \ln P_{j}=-\frac{d \ln \lambda_{j j}}{\varepsilon}+\frac{d \ln N_{j}}{\varepsilon}
$$

Since $d \ln \lambda_{i j}-d \ln \lambda_{j j}=d \ln X_{i j}-d \ln X_{j j}$, Equation (A38) implies, for any $i, i^{\prime} \neq j$,

$$
\frac{\partial \ln \left(X_{i j} / X_{j j}\right)}{\partial \ln \tau_{i^{\prime} j}}=\varepsilon_{j}^{i i^{\prime}}=\left\{\begin{array}{ll}
1-\sigma-\gamma_{i j}+\left(\gamma_{i j}-\gamma_{j j}\right)\left(\frac{\partial \ln \alpha_{j j}^{*}}{\partial \ln \tau_{i j}}\right) & \text { for } \quad i^{\prime}=i \\
\left(\gamma_{i j}-\gamma_{j j}\right)\left(\frac{\partial \ln \alpha_{j j}^{*}}{\partial \ln \tau_{i^{\prime} j}}\right) & \text { for } \quad i^{\prime} \neq i
\end{array} .\right.
$$

Since $\frac{\partial \ln \alpha_{j j}^{*}}{\partial \ln \tau_{i^{\prime} j}}=\frac{\partial \ln P_{j}}{\partial \ln \tau_{i^{\prime} j}}>0$, the two previous equations together with R3 imply $\gamma_{i j}=1-\sigma-\varepsilon$ for all $i$. Combining this observation with Step 3, we get

$$
d \ln P_{j}=\sum_{i=1}^{n} \lambda_{i j}\left(\frac{d \ln \lambda_{i j}-d \ln \lambda_{j j}}{\varepsilon}\right)+\frac{d \ln N_{j}}{\varepsilon} .
$$

Equation (A39) derives from the previous expression and the fact that $\sum_{i=1}^{n} \lambda_{i j} d \ln \lambda_{i j}=0$.

Step 5: Small changes in the number of goods that can be produced satisfy $d \ln N_{j}=0$.

Suppose first that entry is restricted in country $j$. In this case, we immediately get $d \ln N_{j}=0$. Now suppose that we have free entry instead. In this case, we know that $\Pi_{j}=N_{j} F_{j}$. Since $\Pi_{j}=\zeta Y_{j}$ by $\mathrm{R} 1$ and $\mathrm{R} 2$, we therefore have $d \ln N_{j}=d \ln Y_{j}=0$, as demonstrated in Step 1.

Steps 1, 4 and 5 imply $d \ln W_{j}=d \ln \lambda_{j j} / \varepsilon$. The rest of the proof is the same as under perfect competition. QED. 


\section{B Proof of Proposition 2}

Proof of Proposition 2. We first establish Equation (11) for an arbitrary change in variable trade costs from $\boldsymbol{\tau}$ to $\boldsymbol{\tau}^{\prime}$. Like in the proof of Proposition 1, we use labor in country $j$ as our numeraire, $w_{j}=1$. By R3', the shares of expenditures on goods from country $i$ in country $j$ in the initial and new equilibrium, respectively, are given by

$$
\begin{aligned}
\lambda_{i j} & =\frac{\chi_{i j} \cdot N_{i} \cdot\left(w_{i} \tau_{i j}\right)^{\varepsilon}}{\sum_{i^{\prime}=1}^{n} \chi_{i^{\prime} j} \cdot N_{i^{\prime}} \cdot\left(w_{i^{\prime}} \tau_{i^{\prime} j}\right)^{\varepsilon}}, \\
\lambda_{i j}^{\prime} & =\frac{\chi_{i j} \cdot N_{i}^{\prime} \cdot\left(w_{i}^{\prime} \tau_{i j}^{\prime}\right)^{\varepsilon}}{\sum_{i^{\prime}=1}^{n} \chi_{i^{\prime} j} \cdot N_{i^{\prime}}^{\prime} \cdot\left(w_{i^{\prime}}^{\prime} \tau_{i^{\prime} j}^{\prime}\right)^{\varepsilon}} .
\end{aligned}
$$

Using the exact same logic as in the proof of Proposition 1 Step 5, it is easy to check that R1 and R2 imply $\hat{N}_{i}=1$ for all $i=1, \ldots, n$. Combining this observation with Equations $(B 1)$ and $(B 2)$ we obtain

$$
\hat{\lambda}_{i j}=\frac{\left(\hat{w}_{i} \hat{\tau}_{i j}\right)^{\varepsilon}}{\sum_{i^{\prime}=1}^{n} \lambda_{i^{\prime} j}\left(\hat{w}_{i^{\prime}} \hat{\tau}_{i^{\prime} j}\right)^{\varepsilon}} .
$$

Equation (11) directly follows from the previous expression and the fact that $\hat{w}_{j} \hat{\tau}_{j j}=1$ by our choice of numeraire. We now turn to Equation (12) for all $i \neq j$. By R1, we know that in the new equilibrium:

$$
Y_{i}^{\prime}=\sum_{j^{\prime}=1}^{n} \lambda_{i j^{\prime}}^{\prime} Y_{j^{\prime}}^{\prime}
$$

Combining Equations (B3) and (B4) we obtain

$$
Y_{i}^{\prime}=\sum_{j^{\prime}=1}^{n} \frac{\left(\hat{w}_{i} \hat{\tau}_{i j^{\prime}}\right)^{\varepsilon}}{\sum_{i^{\prime}=1}^{n} \lambda_{i^{\prime} j^{\prime}}\left(\hat{w}_{i^{\prime}} \hat{\tau}_{i^{\prime} j^{\prime}}\right)^{\varepsilon}} \lambda_{i j^{\prime}} \hat{Y}_{j^{\prime}} Y_{j^{\prime}}
$$

Using the exact same logic as in the proof of Proposition 1 Step 1, it is also easy to check that R1 and R2 imply $\hat{Y}_{i}=\hat{w}_{i}$ for all $i=1, \ldots, n$. Thus we can rearrange the previous expression as

$$
\hat{w}_{i} Y_{i}=\sum_{j^{\prime}=1}^{n} \frac{\lambda_{i j^{\prime}}\left(\hat{w}_{i} \hat{\tau}_{i j^{\prime}}\right)^{\varepsilon}}{\sum_{i^{\prime}=1}^{n} \lambda_{i^{\prime} j^{\prime}}\left(\hat{w}_{i^{\prime}} \hat{\tau}_{i^{\prime} j^{\prime}}\right)^{\varepsilon}} \cdot \hat{w}_{j^{\prime}} Y_{j^{\prime}} .
$$

Equation (12) directly follows from this expression. QED. 